\title{
Increased SGK1 activity potentiates mineralocorticoid/NaCl-induced hypertension and kidney injury
}

Catalina Sierra-Ramos ${ }^{1}$, Silvia Velazquez-Garcia ${ }^{1,2}$, Ayse G. Keskus $^{3}$, Arianna Vastola-Mascolo ${ }^{1}$, Ana

E. Rodríguez-Rodríguez ${ }^{4}$, Sergio Luis-Lima ${ }^{2,4}$, Guadalberto Hernández ${ }^{1,2}$, Juan F. NavarroGonzález $^{2,5}$, Esteban Porrini2 ${ }^{2,4}$, Ozlen Konu ${ }^{3,6,7}$, Diego Alvarez de la Rosa ${ }^{1,2}$

From ${ }^{1}$ Departamento de Ciencias Médicas Básicas, ${ }^{2}$ Instituto de Tecnologías Biomédicas, Universidad de La Laguna, La Laguna, Tenerife, Spain; ${ }^{3}$ Interdisciplinary Neuroscience Program, Bilkent University, Ankara, Turkey; ${ }^{4}$ Departamento de Medicina Interna, Universidad de La Laguna, La Laguna, Tenerife, Spain; ${ }^{5}$ Unidad de Investigación y Servicio de Nefrología, Hospital Universitario Nuestra Señora de Candelaria, Santa Cruz de Tenerife, Spain; ${ }^{6}$ Department of Molecular Biology and Genetics, Faculty of Science, Bilkent University, Ankara, Turkey; ${ }^{7}$ UNAMInstitute of Materials Science and Nanotechnology, Ankara, Turkey.

Short title: SGK1 in mineralocorticoid-induced hypertension and kidney injury

Corresponding author:

Prof. Diego Alvarez de la Rosa

Departamento de Ciencias Médicas Básicas (Fisiología), Facultad de Medicina, Campus de Ciencias de la Salud s/n, Universidad de La Laguna, 38071 La Laguna, Tenerife, Spain. Telephone: +34-922319-968. Fax: +34-922-319-397. E-mail: diego.alvarez@ull.edu.es

Keywords: serum and glucocorticoid induced kinase 1, aldosterone, mineralocorticoid receptor, chronic kidney disease, fibrosis. 


\begin{abstract}
The serum and glucocorticoid-induced kinase 1 (SGK1) stimulates aldosterone-dependent renal $\mathrm{Na}^{+}$ reabsorption and modulates blood pressure. In addition, genetic ablation or pharmacological inhibition of SGK1 limits the development of kidney inflammation and fibrosis in response to excess mineralocorticoid signalling. In this work we tested the hypothesis that a systemic increase in SGK1 activity would potentiate mineralocorticoid/salt-induced hypertension and kidney injury. To that end, we used a transgenic mouse model with increased SGK1 activity. Mineralocorticoid/salt-induced hypertension and kidney damage was induced by unilateral nephrectomy and treatment with deoxycorticosterone acetate and $\mathrm{NaCl}$ in drinking water for six weeks. Our results demonstrate higher systolic blood pressure in treated transgenic mice when compared to wild type counterparts.

Transgenic mice showed a mild increase in glomerular filtration rate, increased albuminuria, exacerbated glomerular hypertrophy and fibrosis. Transcriptomic analysis showed that extracellular matrix and immune response related terms were enriched in the downregulated and upregulated genes, respectively, in transgenic mice. In conclusion, we propose that systemically increased SGK1 activity is a risk factor for the development of mineralocorticoid-dependent hypertension and incipient kidney injury in the context of low renal mass.
\end{abstract}




\section{INTRODUCTION}

Inappropriately increased mineralocorticoid receptor (MR) signalling plays an important role in the development of chronic kidney disease (CKD) [1]. It has long been known that patients with primary aldosteronism develop hypertension and renal damage. Initially, renal damage was ascribed to increased blood pressure, but it has later been shown that these patients develop kidney injury to a larger extent than comparable individuals with primary hypertension [2]. Extensive work on animal models support a role for aldosterone excess and MR signalling in hypertension-dependent and independent renal damage and progression to CKD [1, 3, 4]. Importantly, preclinical studies conclusively show a major role for MR antagonists in preventing or limiting kidney injury in a large variety of kidney disease models, including hypertension or diabetic nephropathy, glomerulonephritis or transition from acute kidney injury to CKD [3]. These observations have been translated to humans, with data from clinical trials supporting the use of MR inhibition in limiting proteinuria and eliciting renoprotection [3].

The pathophysiological mechanisms involved in the deleterious effects of aldosterone/MR on the kidney expand beyond the role of this system in regulating tubular $\mathrm{Na}^{+}$reabsorption. MR expression has been detected not only in the distal nephron epithelium, but also in podocytes, mesangial cells, endothelial and smooth muscle cells, interstitial fibroblasts and macrophages [3]. Activation of MR in these cell types have been implicated in alterations in renal circulation, oxidative stress, inflammation, glomerular and interstitial fibrosis and alteration of glomerular filtration barrier $[1,3,4]$.

From a molecular perspective, aldosterone/MR-mediated kidney injury likely involves a multiplicity of direct and indirect mechanisms [3]. MR is a nuclear receptor and it is generally assumed that its main long-term effects are mediated by modulation of gene transcription. However, there is still an important knowledge gap about MR gene targets mediating the effects. One interesting candidate to mediate at least part of the processes leading to MR-induced kidney injury and progression to CKD is the serum and glucocorticoid-induced kinase 1 (SGK1), a member of the AGC family of S/T kinases. SGK1 is activated by insulin and several growth factors through the phosphatidylinositol 3-kinase (PI3K) pathway, involving downstream kinases 3-phosphoinositidedependent kinase 1 (PDK1) and mammalian target of rapamycin complex 2 (mTORC2) [5]. SGK1 transcription and translation are tightly regulated and its expression is enhanced by various stimuli including glucocorticoids and mineralocorticoids, being a direct target gene of both MR and the glucocorticoid receptor (GR). The kinase regulates subcellular trafficking of many ion channels and transporters [6], increasing renal $\mathrm{Na}^{+}$reabsorption [7, 8] and $\mathrm{K}^{+}$excretion [9], thus participating in the control of blood pressure. $S g k 1$ knockout protects mice against salt-induced hypertension in a high-fat diet context [10]. Polymorphisms in the human SGK1 gene has been linked to increased blood pressure [11], particularly associated to hyperinsulinemia [12] and the effects of dietary salt intake on blood pressure $[13,14]$. In addition, variants of SGK1 associate to insulin secretion [15] and type 2 
diabetes [16]. Consistently, SGK1 inhibition reduces blood pressure in hyperinsulinemic mice [17] and transgenic SGK1 activation potently induces hypertension in mice treated with a high-fat diet [18].

In addition to regulating transepithelial ion transport, SGK1 has additional cellular functions

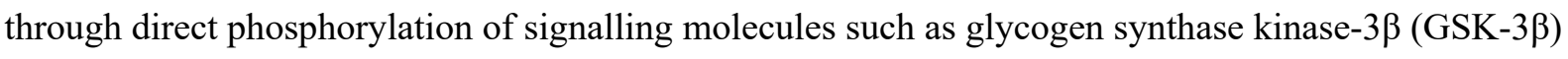
or transcription factors such as members of the FOXO family [19], a pathway that promotes cell survival and proliferation. SGK1 has been implicated in the development of inflammatory and fibrotic processes [20]. Increased SGK1 expression has been described in kidney biopsies from patients with heavy proteinuria [21]. Mice lacking SGK1 show decreased proteinuria and renal fibrosis in response to deoxycorticosterone acetate (DOCA) $/ \mathrm{NaCl}$ treatment [22, 23], suggesting that this gene is key to develop kidney injury in response to excess mineralocorticoids. SGK1 has also been associated to aldosterone-induced oxidative stress and podocyte injury [24]. SGK1 is also expressed in antigenpresenting cells [25] and is important during differentiation of T cells [26], playing a key role in saltsensitive hypertension and renal inflammation [20, 25-27], which further supports a pleiotropic role for SGK1 in kidney disease.

Altogether, the available evidence suggests that increased systemic SGK1 activity could be a common factor underlying blood pressure-sensitive and insensitive pathways leading to renal damage and thus accelerate progression to CKD. To test this hypothesis we took advantage of a transgenic mouse model (Tg.sgk1) previously developed in our laboratory using a modified mouse bacterial artificial chromosome (BAC) that drives the expression of a constitutively active mutant (SGK1$\mathrm{S} 422 \mathrm{D})$ under its own promoter. This transgenic strain provides a model of generalized increase in SGK1 activity without overexpression of the kinase [18, 28, 29]. We used a well-established model of mineralocorticoid excess and high $\mathrm{NaCl}$ intake in the context of uninephrectomy to induce hypertension and renal damage [30,31]. Our results show that increased SGK1 activity induced higher systolic blood pressure after treatment. In addition, transgenic mice displayed exacerbated glomerular hypertrophy, proteinuria and fibrosis with conserved glomerular filtration rate. Finally, we used transcriptomic analysis to define SGK1-modulated pathways in this model. In conclusion, we propose that systemically increased SGK1 activity could be a risk factor for the development of mineralocorticoid-dependent hypertension and kidney injury in the context of low renal mass. 


\section{MATERIAL AND METHODS}

Transgenic expression of constitutively active SGK1 in mice

The generation of transgenic mice expressing a constitutively active mutant of SGK1 (S422D) has been previously described [18, 28, 29]. Briefly, a BAC containing $180 \mathrm{~kb}$ of mouse genomic DNA that includes the full SGK1 gene but no other known or predicted genes was obtained from the BACPAC Resources Center (Children's Hospital Oakland Research Institute, Oakland, CA) and modified by homologous recombination in Escherichia coli to add a constitutively activating point mutation (S422D). Founder animals harbouring the transgene were backcrossed with C57BL/6 mice for eight generations. Mice homozygous for the transgene were obtained by crossing heterozygous animals.

\section{Animal procedures}

All experiments involving mice followed protocols previously approved by the University of La Laguna Ethics Committee on Research and Animal Welfare and were performed in accordance with the European Community guidelines for the use of experimental animals and with Spanish law for the protection of animals. Mice were kept in a 12-hour light/dark cycle at $22^{\circ} \mathrm{C}$ with ad libitum access to food and water. Unilateral nephrectomy (NPX) was performed under isoflurane anaesthesia administered with a vaporizer ( $5 \%$ for induction, $2.5 \%$ for maintenance during surgery).

Buprenorphine (75 $\mu \mathrm{g} / \mathrm{kg}$ body weight $[\mathrm{BW}])$ was administered subcutaneously for peri-operative pain relief. After a two-week recovery period, NPX animals were divided into two groups and treated or not with $1 \% \mathrm{NaCl}$ in drinking water and $75 \mathrm{mg} / \mathrm{kg} \mathrm{BW}$ deoxycorticosterone acetate (DOCA) dissolved in sunflower oil and administered subcutaneously three times a week for six weeks [32] (NDS group). Untreated animals were injected three times weekly with vehicle. Animals from the four experimental groups were housed in metabolic cages. After a two-day adaptation period samples were collected for two consecutive days. Food and water intake and urinary and faecal output were measured daily. Urine samples were centrifuged for $10 \mathrm{~min}$ at $13000 \mathrm{xg}$ and stored at $-80^{\circ} \mathrm{C}$ for further analysis. Urinary $\mathrm{Na}^{+}, \mathrm{K}^{+}$and $\mathrm{Cl}^{-}$content was measured using ion-selective electrodes (Cobas c501, Roche Diagnostics). Urinary creatinine and albumin concentration were measured using commercially available kits (Creatinine Assay Kit and Mouse Albumin ELISA, Abcam). Systolic blood pressure (SBP) was measured by tail cuff plethysmography in trained conscious mice using a non-invasive blood pressure measuring system for rodents (model LE5007, Harvard Apparatus Panlab). Data was acquired with $\mathrm{SeDaCom} 2.0$ software. Measurements were collected for three consecutive days after five days of training. SBP was measured at 20 min intervals for $1 \mathrm{~h}$ between 10 and 11 a.m. GFR measurements used a simplified method of iohexol plasma clearance that we have previously validated in mice [33]. Briefly, a single dose of iohexol (6,47 mg Omnipaque 300, GE Healthcare) was injected intravenously into the tail vein in mice lightly sedated with isoflurane $(2.5 \%)$, administered by facemask while the tail vein was dilated using a heating blanket. Blood samples $(\leq 10 \mu \mathrm{l})$ were collected at $15,35,55$, and 75 min after injection from a small cut in the tail using a heparinized 
capillary tube. Plasma iohexol concentrations were measured by HPLC. Internal calibration curves of iohexol were prepared for each set of samples. Plasma concentrations of iohexol were recalculated from blood levels using the formula: $\mathrm{C}_{\text {plasma }}=\mathrm{C}_{\text {blood }} / 1-\mathrm{Hct}$ where Hct is the haematocrit. Measured iohexol concentrations were fitted by a slope-intercept method according to a one-compartment model simplified method [33]. Fractional excretion of $\mathrm{Na}^{+}\left(\mathrm{FE}_{\mathrm{Na}^{+}}\right)$was expressed as the percentage of the filtered $\mathrm{Na}^{+}$load (calculated from plasma $\mathrm{Na}^{+}$concentration and GFR) excreted in the urine [34]. Tissue sampling, plasma measurements, histological analysis and cell culture After treatments mice were euthanized by carbon dioxide inhalation, and blood was collected by cardiac puncture. Serum corticosterone and aldosterone levels were determined with commercial ELISA kits (DRG Diagnostics). Plasma $\mathrm{Na}^{+}, \mathrm{K}^{+}$and $\mathrm{Cl}^{-}$concentration was measured using ionselective electrodes (Cobas c501, Roche Diagnostics). Tissues were collected from control and treatment groups at the same time and under the same conditions and processed and analysed in parallel. Kidneys were removed, weighed and frozen in liquid nitrogen and stored at $-80^{\circ} \mathrm{C}$ for molecular analysis or fixed by immersion in $4 \%$ formaldehyde, paraffin embedded and processed for histology. Kidney $3 \mu \mathrm{m}$-thick microtome sections were stained with $0.1 \%$ Sirius red in saturated picric acid. Sections were codified to conduct a blinded quantification of fibrosis area. To that end, images from 5 different fields in each section were collected at 40x magnification and fibrotic area was quantified using Fiji software (ImageJ, National Institutes of Health [35]). Two independent experiments were analysed (first experiment, $\mathrm{N}=7$ animals in each group; second experiment, $\mathrm{N}=5$ animals in each group). Primary mouse embryonic fibroblasts (MEFs) were derived from WT and Tg.sgk1 embryos and cultured as described [36].

\section{Microarray analysis and quantitative RT-PCR ( $q P C R)$}

Total RNA was obtained from tissues disrupted with a Tissue Tearor (BioSpec Products) or from cultured cells using a commercial kit (Total RNA Spin Plus, REAL, Valencia, Spain), which includes an in-column treatment with DNase I. Purified total RNA was quantified using a Nanodrop 1000 (Thermo Scientific). Whole-transcriptome analysis was performed using RNA from kidney cortex of nephrectomized, DOCA/NaCl-treated WT and Tg.sgk1 mice ( $\mathrm{N}=4$ in each group). RNA quality analysis was performed using an Agilent 2100 Bioanalyzer. cDNA was synthesized using the GeneChip ${ }^{\circledR}$ WT PLUS Reagent Kit (Affymetrix) and analysed by hybridization to a GeneChip ${ }^{\circledR}$ Mouse Gene 2.0 ST Array (Affymetrix). MIAME-compliant microarray data has been deposited in the Gene Expression Omnibus repository (GEO, National Center for Biotechnology Information, National Institutes of Health) with accession number GSE148880. Raw files were normalized with rma using oligo package in R [37], while differential expression analysis was performed using limma package [38]. A cut-off level of 0.15 (FDR) was used for obtaining the volcano plot (https://github.com/kevinblighe/EnhancedVolcano) and STRING protein-protein interaction network [39], which were visualized in Cytoscape [40]. Gene Ontology (GO) [41] enrichment analysis was performed with an FDR $=0.3$ cut-off using clusterProfiler package in $\mathrm{R}$ [42]. Relative mRNA 
abundance was examined by quantitative RT-PCR (qPCR). Equal amounts of total RNA were processed with the iScript cDNA synthesis kit (Bio-Rad). Gene expression was assessed using commercially available Taqman primer/probe sets (Thermo Fischer) or specific oligonucleotide pairs (Table 1) and SYBR ${ }^{\circledR}$ Green supermix (Bio-Rad). Relative expression of the target genes was calculated with the comparative $\mathrm{C}_{\mathrm{t}}$ method [43] using glyceraldehyde-3-phosphate dehydrogenase (GAPDH) as normalizer.

\section{Western blot}

Protein extracts were obtained from frozen tissue and quantified using the bicinchoninic acid procedure. Equal amounts of protein were resolved on SDS-PAGE (10\% Mini-PROTEAN® TGX Stain-Free ${ }^{\mathrm{TM}}$ Gels, Bio-Rad) and transferred to polyvinyl difluoride membranes (Bio-Rad). Western blots were performed as previously described [44]. Signals were acquired with a chemiluminescent detector (ChemiDoc ${ }^{\mathrm{TM}}$ Imaging System, Bio-Rad) and quantified using software provided by the manufacturer. Phosphorylation of GSK-3 $\alpha / \beta$ at residue Ser21/Ser9 was analysed with a phosphospecific antibody (Cell Signaling, \#9331). Signals were normalized to total expression of GSK-3 $\beta$, obtained with rabbit monoclonal antibody (Cell Signaling \#9315).

\section{Statistical analysis}

Statistical analysis was performed with Prism 8 software (Graphpad, San Francisco, CA). Tests are indicated in each figure or table legend. 


\section{RESULTS}

Transgenic expression of constitutively active SGK1 in the kidney increases phosphorylation of a downstream target

Total expression of SGK1 mRNA was analysed in renal cortex samples of wild type (WT) and Tg.sgk1 mice. We confirmed the expression of the transgene in kidney by RT-PCR using primers flanking the triple HA tag inserted in the COOH-terminus of Tg.sgk1 (Fig. 1A). As we have previously shown in other tissues[28, 29], Tg.sgk1 showed two bands corresponding to the endogenous SGK1 and the HA-labelled transgenic SGK1, respectively, while control animals showed only the lower band corresponding to the endogenous gene (Fig. 1B). The abundance of SGK1 transcript in renal cortex of control and Tg.sgk1 mice was examined by qPCR. Tg.sgk1 showed approximately a two-fold increased expression of SGK1, consistent with the use of a BAC containing the physiological SGK1 promoter (Fig.1C). Treatment with the mineralocorticoid deoxycorticosterone acetate (DOCA) in the context of high $\mathrm{NaCl}$ intake significantly increased SGK1 expression in transgenic, but not in WT animals (Fig. 1C). This suggests that constitutively active SGK1 may potentiate its own expression under certain conditions and is similar to what we have previously found in liver of animals treated with a high-fat diet [18]. In order to check whether transgenic expression of gain-of-function SGK1 mutant produces increased downstream signalling we tested the phosphorylation of GSK-3 $\alpha / \beta$ at residues Ser21/Ser9, a well-known target of SGK1 [45]. Comparison between WT and Tg.sgk1 shows approximately a 50\% increase in pGSK-3 $\alpha / \beta$ abundance (Fig. 1D and $1 \mathrm{E}$ ), in agreement with data obtained from other tissues [18].

Blood pressure increase is more pronounced in uninephrectomized Tg.sgk1 mice treated with $D O C A / \mathrm{NaCl}$

Two-kidney untreated Tg.sgk1 mice did not show any change in systemic blood pressure when compared to WT animals, even when animals where treated with DOCA/ $\mathrm{NaCl}$ (Fig. 2A). Unilateral nephrectomy (NPX) did not alter blood pressure in Tg.sgk1 or WT mice when compared to twokidney animals (Fig. 2A). Blood pressure increased after 4 weeks DOCA/NaCl treatment of NPX animals (NDS challenge), with a larger change in Tg.sgk1 mice (Fig. 2A). NDS lowered aldosterone circulating levels in WT animals, as expected, but no significant changes were detected in NDS Tg.sgk1 animals when compared to NPX (Table 2). There were no differences in water intake, diuresis and plasma or urine electrolytes between genotypes (Table 2).

Excess SGK1 activity exacerbates albuminuria and induces hyperfiltration after nephrectomy and

\section{DOCA/ $\mathrm{NaCl}$ treatment}

Basal urinary albumin/creatinine ratio (uACR) was equal in WT and Tg.sgk1 and was enhanced by DOCA/NaCl treatment (Fig. 3A). Most importantly, uACR was significantly higher in Tg.sgk1 (Fig. 3A), suggesting damage in the glomerular filtration barrier. To evaluate the effect of SGK1 on glomerular function during the NDS challenge we measured GFR and urinary albumin excretion. Iohexol clearance measurements did not reveal any significant difference between untreated WT and 
Tg.sgk1 mice (Fig. 3B), with GFR values consistent with our previously reported results for male mice from the same strain [33]. NPX induced a decrease in GFR, as expected, with no significant differences between genotypes (Fig. 3B). When NPX animals were treated with DOCA/NaCl, GFR increased significantly only in Tg.sgk1, but not in WT animals (Fig. 3B).

Tg.sgk1 display aggravated glomerular hypertrophy, fibrosis and inflammation under NDS treatment NDS treatment significantly increased kidney weight in both WT and transgenic animals, without significant differences between genotypes (Table 2). Evaluation of excess SGK1 activity on NDSinduced changes in kidney morphology and fibrosis was analysed using Sirius Red staining (Fig. 4A and 4B). Upon NPX, Tg.sgk1 showed glomerular hypertrophy, an effect that was further potentiated when animals were treated with DOCA/ $\mathrm{NaCl}$ (Fig. 4A). Quantification of Sirius Red-positive area in kidney cortex revealed increased glomerular and interstitial fibrosis, with a tendency towards increased perivascular fibrosis, in Tg.sgk1 mice when compared to WT mice after NDS (Fig. 4C). We next examined the expression of molecular markers of fibrosis in kidney cortex. SGK1 has previously been implicated in promoting the expression of connective tissue growth factor (CTGF) [46], a gene involved in the pathogenesis of fibrosis. DOCA/ $\mathrm{NaCl}$ treatment significantly increased CTGF expression in transgenic animals, but not in their wild-type counterparts. There was no significant induction of TGF- $\beta 1$ (Fig. 4D), consistently with the previously described aldosterone-induced profibrotic pathway mediated by CTGF through a TGF- $\beta 1$-independent pathway [47]. Fibronectin and collagen IV were also significantly more upregulated in transgenics, while $\alpha$-SMA showed a tendency towards increased expression after DOCA/ $\mathrm{NaCl}$ in both Tg.sgk1 and WT mice. Surprisingly, collagen I was less induced in transgenics than in WT (Fig. 4D). Expression of monocyte chemoattractant protein-1 (MCP-1, Ccl2), a marker of inflammation, was significantly upregulated by NDS challenge, although induction was slightly smaller in Tg.sgk1. mice (Fig. 4D).

\section{Limited tubular injury in Tg.sgk1 mice}

Given the increased tubulointerstitial fibrosis in Tg.sgk1 animals, we asked whether tubular function and/or markers of tubular injury are altered in transgenic mice. To functionally assess possible tubular injury, we measured fractional excretion of $\mathrm{Na}^{+}\left(\mathrm{FE}_{\mathrm{Na}+}\right)$. $\mathrm{FE}_{\mathrm{Na}}$ in NPX mice was undistinguishable between WT and Tg.sgk1 (approx. 0.3\%; Fig. 5A) and within the normal range [34, 48]. DOCA/NaCl increased $\mathrm{FE}_{\mathrm{Na}}$, as expected, but no significant difference was detected between WT and transgenic mice (Fig. 5A). NGAL (lipocalin 2) and KIM-1 are markers of tubular injury [49]. We detected significantly increased NGAL expression in DOCA/NaCl-treated transgenic animals (Fig. 5B). Taken together, these results suggest limited tubular injury in this model.

\section{Differentially regulated genes in $\mathrm{Tg} . \mathrm{sgkl}$ in response to $\mathrm{DOCA} / \mathrm{NaCl}$}

To identify potential genes involved in the aggravated kidney injury observed in Tg.sgk1 following NDS we performed whole-transcriptome analysis using microarrays. Our analysis compared WT and Tg.sgk1 mice subject to the challenge ( $\mathrm{N}=4$ in each group). Differential expression (DE) analysis by limma resulted in identification of 198 probesets of which 120 were up-regulated and 78 were down- 
regulated at the given false discovery rate (FDR $<0.15$; (on-line supplementary information, Table S1) based the volcano plot (Fig. 6A). Among these significantly modulated genes there were more upregulated $(n=38)$ than down-regulated $(n=9)$ probesets exhibiting a $\log 2$ fold change greater than or equal to one (red probesets; Fig. 6A). $C p b 2$ and Serpindla were the most significantly modulated upregulated and down-regulated genes, respectively (Supplementary Table S1). The hierarchical clustering of expression values of the genes obtained from the DE analysis demonstrated that there were two main clusters separating samples from WT and Tg.Sgk1 animals, respectively, as well as two clusters of genes exhibiting up-regulation and down-regulation of expression (Fig. 6B) with relatively stable within-cluster variability. The gene modules obtained for proteins with a physicaland/or context-driven interaction (String Database) between them were drawn by Cytoscape and helped identify the specific gene clusters/modules for the DE genes. There were two relatively large gene modules with 15 and 8 members, each, respectively. The 15-member gene network included the most significantly upregulated gene, $C p b 2$, along with several genes involved in collagen fibril formation, e.g., Loxl, Collal and Col27al (Fig. 6C). On the other hand, 8-members gene network included mostly Serpina gene family in which Serpinal and Serpina 3 genes were down- and upregulated, respectively (Fig. 6C). Two other smaller networks were also observed; one contained upregulated members of cytoplasmic dynein family (Dynlt1) genes, known to be involved in vesicle transport, while the other gene module included down-regulated genes with relatively less well-known functions in the literature (Fig. 6C). Several other 3- or 2-member networks also emerged. We then performed a GO term enrichment analysis using ClusterProfiler package in R separately for up- and down-regulated genes, based on a less stringent FDR cut-off value (i.e., $<0.3$; Supplementary Table S2). The resulting pathways for down-regulated genes included those involved in extracellular matrix (ECM) formation while up-regulated genes belonged to mostly immune response pathways, phagocytosis as well as lipid metabolism (Fig. 7; Supplementary Tables S3 and S4).

Among differentially regulated genes detected by microarray analysis, we selected 5 upregulated genes (Cpb2, Lyplal1, Serpina3b, Ccl28 and Col27al) and 1 down-regulated gene (Adamtsl2) to confirm microarray data by quantitative PCR. To that end, we analysed a higher number of animals of the same cohort used to perform transcriptomics $(\mathrm{N}=6)$ and expanded the analysis to the four groups of animals used throughout this study (NPX WT or Tg.sgk1, with or without DOCA $/ \mathrm{NaCl}$ treatment). Our results were in accordance to the microarray analysis, showing that the expression of every gene tested was significantly different between WT-NDS and Tg-NDS (Fig. 8A). Interestingly, when the four experimental groups were examined in parallel, we detected three different patterns of regulation by SGK1 activity and DOCA/NaCl treatment. $C p b 2, C c l 28$ and Serpina $3 b$ were upregulated by increased SGK1 activity, but DOCA/ $\mathrm{NaCl}$ did not further increase their expression (Fig. 8A). This is also the case of the Adamtsl2, which was downregulated by increased SGK1 activity, but unaffected by DOCA/NaCl treatment (Fig. 8A). Lyplal1 was also upregulated by increased SGK1 activity, but DOCA/ $\mathrm{NaCl}$ additively increased its expression (Fig. 
8A). In contrast, Col27A1 was only upregulated by the synergism between increased SGK1 activity and DOCA/ $\mathrm{NaCl}$ treatment (Fig. 8A). We then investigated whether these genes are direct targets of SGK1 signalling or, alternatively, whether their regulation is secondary to the deleterious effects induced by the transgene. To that end we obtained primary mouse embryonic fibroblasts (MEFs) from WT or transgenic animals (Fig. 8B). Of the six genes analysed, Col27a1, Lyplall and Ccl28 were detectable in both WT- and Tg.sgk1-derived MEFs (Fig. 8C). As expected from the results obtained from kidney samples, Lyplall expression was significantly higher in MEFs derived from Tg.sgk1 (Fig. 8C). In contrast $C c l 28$ expression was not significantly different between MEFs with the two different genotypes, suggesting that the upregulation detected in vivo may be secondary to other processes triggered by SGK1 in the kidney. Col27A1 did not show any difference in expression, consistent with the results obtained from animals. 


\section{DISCUSSION}

This study tested the hypothesis that increased systemic SGK1 activity constitutes a common factor underlying blood pressure-sensitive and insensitive renal damage secondary to excess mineralocorticoid signalling. To that end, we chose our previously characterized transgenic mouse model with expression of a constitutively active mutant of SGK1 expressed from a BAC [18, 28, 29]. This model has the advantage of expressing SGK1 under the control of its own promoter, avoiding overexpression of the kinase but at the same time enhancing downstream signalling. To produce mineralocorticoid-induced increases in blood pressure and development of kidney injury we used the DOCA $/ \mathrm{NaCl}$ model, which in mice have to be performed in the context of low renal mass (uninephrectomy). Under these conditions, transgenic mice showed significantly increased blood pressure, albuminuria, hyperfiltration, glomerular hypertrophy and fibrosis when compared to their WT counterparts, consistent with accelerated kidney damage.

Our results support increased SGK1 activity as a risk factor for the development of mineralocorticoid-dependent kidney injury. In addition, the results shed light on the contribution of the kinase to hypertension-dependent and -independent pathways of renal damage. On one hand, our data showed that SGK1 enhances mineralocorticoid-induced increased blood pressure. This is consistent with previous data implicating SGK1 in the control of blood pressure in humans and mice. SGK1 polymorphisms associate with increased blood pressure, hyperinsulinemia [12] and type 2 diabetes [16] in humans. Sgk1 knockout mice maintain blood pressure at the expense of increased circulating aldosterone and this strain is unable to maximally activate $\mathrm{Na}^{+}$reabsorption after a low $\mathrm{Na}^{+}$challenge [8]. Lack of $S g k 1$ precludes salt-induced hypertension in a high-fat diet context [10] and angiotensin II-induced hypertension [27]. Data from our studies expand these observations, showing that enhanced kinase activity exacerbates blood pressure increases in models with high-fat diet [18] and increased mineralocorticoid signalling.

A relevant finding of our study was that renal damage was only observed in the presence of a relevant reduction of renal mass (uninephrectomy). This indicates an interaction between a low nephron endowment and SGK1-mediated effects in the induction of renal damage in the context of hypertension. The incidence and prevalence of CKD do not match that of hypertension in humans. Recent studies indicated that not all subjects with hypertension are at risk for renal disease, only those with concomitant risk factors like metabolic syndrome or low renal mass [50]. In fact, a lower number of glomeruli has been associated with a higher risk of hypertension [51]. Also, living kidney donors, a healthy population, have an increased risk of hypertension after donation, compared to matched healthy controls that did not undergo a nephrectomy [52]. These data, together with our results may support the hypothesis that a reduction of renal mass in necessary to induce hypertension and that SGK1 may play a role in the pathogenesis of renal disease in this context.

On the other hand, our data also suggests that SGK1 may potentiate hypertension-independent kidney damage. It is important to note that blood pressure increase in the NDS model used in this 
study is modest when compared to the much larger effect that the kinase had in the context of a highfat diet using the same transgenic mouse [18], with an average SBP of $170 \mathrm{mmHg}$ after just 7 weeks of treatment ( $40 \%$ higher than WT animals). Analysis of these animal cohorts did not show differences in glomerular size or kidney fibrosis (Vastola-Mascolo, Velázquez-García and Alvarez de la Rosa, unpublished observations), indicating that during the time-frame used in this and our previously published studies (6-7 weeks) increased blood pressure alone is insufficient to produce kidney damage, at least in this genetic background. On the other hand, transgenic NPX animals (not treated with $\mathrm{DOCA} / \mathrm{NaCl}$ ) already demonstrated glomerular hypertrophy (Fig. 4A), even though there is no difference in SBP between both genotypes (Fig. 2B). Taken together, these results support a role for SGK1 in the early stages of hypertension-independent kidney damage. This is consistent with previously published observations showing that DOCA/NaCl-treated WT and $\mathrm{Sgkl} \mathrm{I}^{-/-}$mice had similar blood pressures but only WT mice developed albuminuria and renal fibrosis [22].

The mechanisms involved in SGK1 contribution to development of glomerular hypertrophy and glomerular barrier damage are probably diverse. MR-dependent up-regulation of SGK1 in podocytes is linked to aldosterone-mediated oxidative stress and glomerular damage [24]. In addition, SGK1 increases ICAM-1 and CTGF expression in mesangial cells, promoting inflammatory and fibrotic responses [53]. Our results show increased CTGF expression without changes in TGF- $\beta 1$ expression in Tg.sgk1, which is consistent with changes reported in aldosterone-induced fibrosis in a rat model of diabetic nephropathy [47]. Our results are also in agreement with the lack of TGF- $\beta 1$ induction in the heart of DOCA/NaCl-treated mice [46] or rats [54] and the fact that CTGF can be induced independently of TGF- $\beta 1$ in human mesangial cells [55]. In addition, $S g k 1$ transcription is upregulated by TGF- $\beta 1[56]$ and therefore constitutive activation of the kinase appears to control downstream pro-fibrotic pathways. An additional convergence point between SGK1 and TGF- $\beta$ signalling is provided by NEDD4-L, a ubiquitin ligase which modifies and targets for degradation Smad2/3, mediators of the canonical TGF- $\beta$-regulated transcriptional response. SGK1 phosphorylates NEDD4-L, preventing its interaction with Smad2/3 and therefore potentiating TGF- $\beta$ signalling [57]. We can also speculate about additional pathways that may contribute to the harmful renal SGK1 effects. For instance, insulin-like growth factor-1 (IGF-1), which has been implicated in glomerular hypertrophy in the remnant kidney of NPX model [58], activates the PI3K pathway and SGK1 is one of the mediators of this pathway. Enhanced activity of MR in additional cell types, such as inflammatory cells, smooth muscle cells or the endothelium may cause damage to kidney structure and function. We have already mentioned that SGK1 expression on antigen-presenting cells contributes to renal inflammation [25]. In contrast, endothelial MR knockout prevents cardiac but not renal damage induced by DOCA/ $\mathrm{NaCl}$ [59]. Therefore, SGK1-mediated effects detected in our study are likely independent of endothelial cell function. 
In order to better understand the basic mechanism involved in SGK1-mediated kidney damage we compared whole transcriptome profiles of kidney cortex in WT and Tg.sgk1 mice in the NDS model. We detected 120 up-regulated and 78 down-regulated genes in transgenic mice (FDR $<0.15)$. To validate microarray results and assess whether our strategy was able to identify genes potentially involved in the exacerbation of DOCA/ $\mathrm{NaCl}$ kidney injury we further studied five up-regulated and one down-regulated genes in an independent cohort of animals including the four experimental groups used throughout this study (NPX WT or Tg.sgk1, with or without DOCA/ $\mathrm{NaCl}$ treatment). In every gene tested we were able to confirm the microarray analysis. Furthermore, we detected different regulation patterns by SGK1 and DOCA/ $\mathrm{NaCl}$ treatment. Interestingly, Col27al expression was not significantly affected by increased SGK1 activity in the kidney cortex or in cultured primary MEFs. However, the combination of increased SGK1 activity and DOCA/NaCl treatment produced a synergistic increase in Col27al. Col27al, a little known fibrillar collagen gene that plays a role during the calcification of cartilage and the transition of cartilage to bone $[60,61]$, has not been previously linked to kidney fibrosis. This result is highly significant, since it validates our strategy to identify genes potentially involved in the amplification of DOCA/NaCl kidney injury by SGK1 activity.

Analysis of gene modules formed by differentially expressed genes uncovered one cluster related to collagen fibril formation (including Col27al, Collal and Loxl) and the fibrinolytic system (including $C p b 2$ ), which has also been implicated in the regulation of renal fibrosis [62]. GO term enrichment analysis showed an overall down-regulation of genes involved in ECM formation. While this last result may seem paradoxical, taken together the analysis strongly suggests that increased SGK1 leads to dysregulation of pathways controlling ECM remodelling [63]. This idea is supported by our analysis of classical fibrosis markers showing the expected overexpression of CTGF, fibronectin and collagen IV in Tg.sgk1 mice, but not significant changes in TGF- $\beta 1$ or $\alpha$-SMA, suggesting alternative pathways for fibrosis development [47]. Also, in agreement with this view are previous reports in the literature showing several downregulated ECM components associated with the development of fibrosis. For instance, decorin, one of the down-regulated genes in our gene list, is antifibrotic and decorin knockout mice show increased ECM accumulation in diabetic nephropathy [64]. Decorin sequesters TGF- $\beta$ [65] and therefore its downregulation may enhance signalling through this pathway without alterations in TGF- $\beta$ mRNA expression. Two membrane-bound matrix metalloproteinases (MMP14 and MMP15) also come up among the downregulated genes. There is strong evidence pointing to dysregulation of MMPs in a wide variety of kidney diseases, including acute kidney injury, diabetic nephropathy, glomerulonephritis [66]. MMP14 cleaves several ECM proteins, including collagen I, fibronectin and laminin [67]. Therefore, MMP14 has a degradative rather than synthetic role and its deficiency leads to fibrosis without altering collagen synthesis [68, 69]. In addition, both MMP14 and MMP15 activate the gelatinase MMP2, which together with MMP9 has extensive implications in kidney disease [67]. NGAL, which was found to be upregulated in our analysis, stabilizes MMP9 potentiating its function [70]. 
Some genes previously characterized as profibrotic showed lower expression in Tg.sgk1 when compared to WT mice. For instance, Loxl1, a member of the lysyl-oxidase-like family, crosslinks collagen and elastin and has been implicated in fibrogenesis [71]. Similarly, upregulation of Loxl2 may lead to kidney fibrosis in Col4a3 null mice [72]. On the other hand, there are reports showing that downregulation Loxl2 may increase collagen formation via activation of TGF- $\beta /$ Smad pathway in preeclamptic placenta [73]. This suggests that tissue specificity as well as genetic background may determine the effects of ECM regulators such as Loxl2. Fbln5 (fibulin-5) [74] and Serpinh1 [75] expression has been linked to development of kidney fibrosis as well. In addition to the hypothesis that these differentially expressed genes are further indication of dysregulated ECM turnover, it is conceivable that some of them may reflect negative feedback loops limiting the extent of fibrosis development. It is likely that both hypotheses are correct, depending on which individual gene or signalling pathway is being considered.

As mentioned above, the largest gene cluster obtained in our analysis included genes related not only to collagen fibril formation, but also to the fibrinolytic system, which participates in development of renal fibrosis [62]. Mice deficient in Cpb2 (carboxypeptidase B2, also known as thrombin-activated fibrinolysis inhibitor -TAFI-), the most upregulated gene in the microarray, have better survival and less kidney injury in a sepsis model [76]. Cpb2/TAFI polymorphisms associate with CKD frequency in a human population [77], while its level show strong correlation with kidney function impairment. In addition, CPB2/TAFI inhibition ameliorates kidney fibrosis in an animal model of CKD [62]. Therefore, our results support a role for the fibrinolytic axis in exacerbated fibrosis observed in Tg.sgk1 mice.

The second largest cluster obtained by gene module analysis includes several members of the serine protease inhibitor clade A (Serpina) family. Serpinal (alpha-1-antitrypsin, AAT), the most downregulated gene in the microarray, has been shown to be the most abundant serine protease inhibitor with prominent anti-inflammatory and tissue-protective effects. Serpin1a knockout mice develop lung emphysema [78] and liver fibrosis [79]. In addition, AAT therapy protects against kidney injury secondary to ischemia-reperfusion [80]. On the other hand, serpina3, a well-known MR target [81] recently proposed as a renal fibrosis and inflammation marker during transition to CKD [82], is potently upregulated in Tg.sgk1 mice. Accordingly, our findings implicate abnormal accumulation and turnover of a network of ECM proteins in SGK1-driven fibrosis in early-stage CKD.

GO enrichment analysis for up-regulated genes uncovered mostly immune response pathways, phagocytosis and lipid metabolism. Modulation of immune response and phagocytosis pathways is in good agreement with the well-established role of SGK1 in salt-sensitive hypertension and renal injury through its expression in T cells and antigen-presenting cells [20, 25-27]. In fact, T cell-specific and dendritic cell-specific $S g k l$ knockout abrogates increased blood pressure, vascular and renal inflammation in response to DOCA/NaCl treatment [27] and the L-NAME high-salt protocol [25], respectively. Ccl28 (C-C motif chemokine ligand 28), a prominently up-regulated gene in Tg.sgk1, 
has previously been characterized as lymphocyte homing factor in mucosal tissues [83] and was recently associated with the accumulation of $\mathrm{B}$ and $\mathrm{T}$ lymphocytes in the kidney during the transition from acute to chronic injury [84]. In addition, the list of differentially expressed genes includes several up-regulated genes coding for immunoglobulin chains. Taken together, our data not only supports the notion that SGK1 is a key component on T cell infiltration and inflammation in salt-sensitive kidney injury, but also supports a role for B cell infiltration in the process [85].

It is important to acknowledge several limitations in our study. First, for practical reasons we only performed experiments on male mice only. However, based on the known sexual dimorphism in blood pressure-dependent and -independent responses in mice [86, 87], additional experiments are needed to assess the role of SGK1 activity on female mice. Also, SGK1 effects on the DOCA/NaCl model are predictably the result of a synergy between pathways regulating renal ion transport, podocyte and mesangial cell function, ECM turnover and inflammatory responses. Dissecting the role of excess SGK1 activity in each of these components will require using tissue-specific, conditional SGK1 gain-of-function models.

In summary, our results support the idea that systemically increased SGK1 activity is a risk factor for the development of mineralocorticoid-dependent hypertension and incipient kidney damage, particularly in the context of low renal mass, potentially accelerating the progression to CKD. SGK1 activity alters pathways related to ECM turnover and immune system responses and may provide a therapeutic target to delay CKD development.

\section{CLINICAL PERSPECTIVES}

1. Background. Excess aldosterone induces hypertension-dependent and -independent renal damage and progression to CKD. Protein kinase SGK1 is upregulated by aldosterone, has been linked to increased blood pressure and is pro-inflammatory and pro-fibrotic. Thus, increased SGK1 activity may represent a risk factor for accelerated renal damage.

2. Summary of the results. Increased SGK1 activity in the context of low renal mass and mineralocorticoid excess for salt status increases blood pressure and accelerates renal damage, with underlying alterations on extracellular matrix remodeling and immune response pathways.

\section{Potential significance of the results to human health and disease. Increased SGK1 expression could} be a marker for rapid progression towards CKD and a potential therapeutic target to slow down the process. 


\section{REFERENCES}

1 Bertocchio, J. P., Warnock, D. G. and Jaisser, F. (2011) Mineralocorticoid receptor activation and blockade: an emerging paradigm in chronic kidney disease. Kidney Int. 79, 1051-1060 2 Rossi, G. P., Bernini, G., Desideri, G., Fabris, B., Ferri, C., Giacchetti, G., Letizia, C., Maccario, M., Mannelli, M., Matterello, M.-J., Montemurro, D., Palumbo, G., Rizzoni, D., Rossi, E., Pessina, A. C. and Mantero, F. (2006) Renal Damage in Primary Aldosteronism. Hypertension. 48, $232-238$

3 Barrera-Chimal, J., Girerd, S. and Jaisser, F. (2019) Mineralocorticoid receptor antagonists and kidney diseases: pathophysiological basis. Kidney Int. 96, 302-319

4 Shibata, S. and Fujita, T. (2012) Mineralocorticoid receptors in the pathophysiology of chronic kidney diseases and the metabolic syndrome. Mol Cell Endocrinol. 350, 273-280

5 Garcia-Martinez, J. M. and Alessi, D. R. (2008) mTOR complex 2 (mTORC2) controls hydrophobic motif phosphorylation and activation of serum- and glucocorticoid-induced protein kinase 1 (SGK1). Biochem J. 416, 375-385

6 Valinsky, W. C., Touyz, R. M. and Shrier, A. (2018) Aldosterone, SGK1, and ion channels in the kidney. Clin Sci (Lond). 132, 173-183

7 Faresse, N., Lagnaz, D., Debonneville, A., Ismailji, A., Maillard, M., Fejes-Toth, G., NarayFejes-Toth, A. and Staub, O. (2012) Inducible kidney-specific Sgk1 knockout mice show a salt-losing phenotype. Am J Physiol Renal Physiol. 302, F977-985

8 Wulff, P., Vallon, V., Huang, D. Y., Volkl, H., Yu, F., Richter, K., Jansen, M., Schlunz, M., Klingel, K., Loffing, J., Kauselmann, G., Bosl, M. R., Lang, F. and Kuhl, D. (2002) Impaired renal $\mathrm{Na}(+)$ retention in the sgk1-knockout mouse. J Clin Invest. 110, 1263-1268

9 Al-Qusairi, L., Basquin, D., Roy, A., Stifanelli, M., Rajaram, R. D., Debonneville, A., Nita, I., Maillard, M., Loffing, J., Subramanya, A. R. and Staub, O. (2016) Renal tubular SGK1 deficiency causes impaired $\mathrm{K}+$ excretion via loss of regulation of NEDD4-2/WNK1 and ENaC. Am J Physiol Renal Physiol. 311, F330-342

10 Huang, D. Y., Boini, K. M., Osswald, H., Friedrich, B., Artunc, F., Ullrich, S., Rajamanickam, J., Palmada, M., Wulff, P., Kuhl, D., Vallon, V. and Lang, F. (2006) Resistance of mice lacking the serum- and glucocorticoid-inducible kinase SGK1 against salt-sensitive hypertension induced by a high-fat diet. Am J Physiol Renal Physiol. 291, F1264-1273

11 Busjahn, A., Aydin, A., Uhlmann, R., Krasko, C., Bahring, S., Szelestei, T., Feng, Y., Dahm, S., Sharma, A. M., Luft, F. C. and Lang, F. (2002) Serum- and glucocorticoid-regulated kinase (SGK1) gene and blood pressure. Hypertension. 40, 256-260

12 von Wowern, F., Berglund, G., Carlson, J., Mansson, H., Hedblad, B. and Melander, O.

(2005) Genetic variance of SGK-1 is associated with blood pressure, blood pressure change over time and strength of the insulin-diastolic blood pressure relationship. Kidney Int. 68, 2164-2172 
13 Li, C., Yang, X., He, J., Hixson, J. E., Gu, D., Rao, D. C., Shimmin, L. C., Huang, J., Gu, C. C., Chen, J., Li, J. and Kelly, T. N. (2014) A gene-based analysis of variants in the serum/glucocorticoid regulated kinase (SGK) genes with blood pressure responses to sodium intake: the GenSalt Study. PLoS One. 9, e98432

14 Rao, A. D., Sun, B., Saxena, A., Hopkins, P. N., Jeunemaitre, X., Brown, N. J., Adler, G. K. and Williams, J. S. (2013) Polymorphisms in the serum- and glucocorticoid-inducible kinase 1 gene are associated with blood pressure and renin response to dietary salt intake. J Hum Hypertens. 27, 176180

15 Friedrich, B., Weyrich, P., Stancakova, A., Wang, J., Kuusisto, J., Laakso, M., Sesti, G., Succurro, E., Smith, U., Hansen, T., Pedersen, O., Machicao, F., Schafer, S., Lang, F., Risler, T., Ullrich, S., Stefan, N., Fritsche, A. and Haring, H. U. (2008) Variance of the SGK1 gene is associated with insulin secretion in different European populations: results from the TUEF, EUGENE2, and METSIM studies. PLoS One. 3, e3506

16 Schwab, M., Lupescu, A., Mota, M., Mota, E., Frey, A., Simon, P., Mertens, P. R., Floege, J., Luft, F., Asante-Poku, S., Schaeffeler, E. and Lang, F. (2008) Association of SGK1 gene polymorphisms with type 2 diabetes. Cell Physiol Biochem. 21, 151-160

17 Ackermann, T. F., Boini, K. M., Beier, N., Scholz, W., Fuchss, T. and Lang, F. (2011)

EMD638683, a novel SGK inhibitor with antihypertensive potency. Cell Physiol Biochem. 28, 137146

18 Sierra-Ramos, C., Velazquez-Garcia, S., Vastola-Mascolo, A., Hernandez, G., Faresse, N. and Alvarez de la Rosa, D. (2020) SGK1 activation exacerbates diet-induced obesity, metabolic syndrome and hypertension. J Endocrinol. 244, 149-162

19 Brunet, A., Park, J., Tran, H., Hu, L. S., Hemmings, B. A. and Greenberg, M. E. (2001) Protein kinase SGK mediates survival signals by phosphorylating the forkhead transcription factor FKHRL1 (FOXO3a). Mol Cell Biol. 21, 952-965

20 Artunc, F. and Lang, F. (2014) Mineralocorticoid and SGK1-sensitive inflammation and tissue fibrosis. Nephron Physiol. 128, 35-39

21 Quinkler, M., Zehnder, D., Eardley, K. S., Lepenies, J., Howie, A. J., Hughes, S. V., Cockwell, P., Hewison, M. and Stewart, P. M. (2005) Increased expression of mineralocorticoid effector mechanisms in kidney biopsies of patients with heavy proteinuria. Circulation. 112, 14351443

22 Artunc, F., Amann, K., Nasir, O., Friedrich, B., Sandulache, D., Jahovic, N., Risler, T., Vallon, V., Wulff, P., Kuhl, D. and Lang, F. (2006) Blunted DOCA/high salt induced albuminuria and renal tubulointerstitial damage in gene-targeted mice lacking SGK1. J Mol Med (Berl). 84, 737-746 23 Vallon, V., Huang, D. Y., Grahammer, F., Wyatt, A. W., Osswald, H., Wulff, P., Kuhl, D. and Lang, F. (2005) SGK1 as a determinant of kidney function and salt intake in response to mineralocorticoid excess. Am J Physiol Regul Integr Comp Physiol. 289, R395-R401 
24 Shibata, S., Nagase, M., Yoshida, S., Kawachi, H. and Fujita, T. (2007) Podocyte as the target for aldosterone: roles of oxidative stress and Sgk1. Hypertension. 49, 355-364

25 Van Beusecum, J. P., Barbaro, N. R., McDowell, Z., Aden, L. A., Xiao, L., Pandey, A. K., Itani, H. A., Himmel, L. E., Harrison, D. G. and Kirabo, A. (2019) High Salt Activates CD11c(+) Antigen-Presenting Cells via SGK (Serum Glucocorticoid Kinase) 1 to Promote Renal Inflammation and Salt-Sensitive Hypertension. Hypertension. 74, 555-563

26 Wu, C., Yosef, N., Thalhamer, T., Zhu, C., Xiao, S., Kishi, Y., Regev, A. and Kuchroo, V. K. (2013) Induction of pathogenic TH17 cells by inducible salt-sensing kinase SGK1. Nature. 496, 513517

27 Norlander, A. E., Saleh, M. A., Pandey, A. K., Itani, H. A., Wu, J., Xiao, L., Kang, J., Dale, B. L., Goleva, S. B., Laroumanie, F., Du, L., Harrison, D. G. and Madhur, M. S. (2017) A salt-sensing kinase in T lymphocytes, SGK1, drives hypertension and hypertensive end-organ damage. JCI Insight. 2

28 Andres-Mateos, E., Brinkmeier, H., Burks, T. N., Mejias, R., Files, D. C., Steinberger, M., Soleimani, A., Marx, R., Simmers, J. L., Lin, B., Finanger Hedderick, E., Marr, T. G., Lin, B. M., Hourde, C., Leinwand, L. A., Kuhl, D., Foller, M., Vogelsang, S., Hernandez-Diaz, I., Vaughan, D. K., Alvarez de la Rosa, D., Lang, F. and Cohn, R. D. (2013) Activation of serum/glucocorticoidinduced kinase 1 (SGK1) is important to maintain skeletal muscle homeostasis and prevent atrophy. EMBO Mol Med. 5, 80-91

29 Miranda, P., Cadaveira-Mosquera, A., Gonzalez-Montelongo, R., Villarroel, A., GonzalezHernandez, T., Lamas, J. A., Alvarez de la Rosa, D. and Giraldez, T. (2013) The neuronal serum- and glucocorticoid-regulated kinase 1.1 reduces neuronal excitability and protects against seizures through upregulation of the M-current. J Neurosci. 33, 2684-2696

30 Hartner, A., Cordasic, N., Klanke, B., Veelken, R. and Hilgers, K. F. (2003) Strain differences in the development of hypertension and glomerular lesions induced by deoxycorticosterone acetate salt in mice. Nephrol Dial Transplant. 18, 1999-2004

31 Johns, C., Gavras, I., Handy, D. E., Salomao, A. and Gavras, H. (1996) Models of experimental hypertension in mice. Hypertension. 28, 1064-1069

32 Nakano, D., Kwak, C. J., Fujii, K., Ikemura, K., Satake, A., Ohkita, M., Takaoka, M., Ono, Y., Nakai, M., Tomimori, N., Kiso, Y. and Matsumura, Y. (2006) Sesamin metabolites induce an endothelial nitric oxide-dependent vasorelaxation through their antioxidative property-independent mechanisms: possible involvement of the metabolites in the antihypertensive effect of sesamin. $\mathrm{J}$ Pharmacol Exp Ther. 318, 328-335

33 Luis-Lima, S., Rodriguez-Rodriguez, A. E., Martin-Higueras, C., Sierra-Ramos, C., Carrara, F., Arnau, M. R., Alvarez de la Rosa, D., Salido, E., Gaspari, F. and Porrini, E. (2016) Iohexol plasma clearance, a simple and reliable method to measure renal function in conscious mice. Pflugers Arch.

468, $1587-1594$ 
34 Ivy, J. R., Evans, L. C., Moorhouse, R., Richardson, R. V., Al-Dujaili, E. A. S., Flatman, P. W., Kenyon, C. J., Chapman, K. E. and Bailey, M. A. (2018) Renal and Blood Pressure Response to a High-Salt Diet in Mice With Reduced Global Expression of the Glucocorticoid Receptor. Front Physiol. 9, 848

35 Schindelin, J., Arganda-Carreras, I., Frise, E., Kaynig, V., Longair, M., Pietzsch, T., Preibisch, S., Rueden, C., Saalfeld, S., Schmid, B., Tinevez, J. Y., White, D. J., Hartenstein, V., Eliceiri, K., Tomancak, P. and Cardona, A. (2012) Fiji: an open-source platform for biological-image analysis. Nat Methods. 9, 676-682

36 Garfield, A. S. (2010) Derivation of primary mouse embryonic fibroblast (PMEF) cultures. Methods Mol Biol. 633, 19-27

37 Carvalho, B. S. and Irizarry, R. A. (2010) A framework for oligonucleotide microarray preprocessing. Bioinformatics. 26, 2363-2367

38 Ritchie, M. E., Phipson, B., Wu, D., Hu, Y., Law, C. W., Shi, W. and Smyth, G. K. (2015) limma powers differential expression analyses for RNA-sequencing and microarray studies. Nucleic Acids Res. 43, e47

39 Szklarczyk, D., Gable, A. L., Lyon, D., Junge, A., Wyder, S., Huerta-Cepas, J., Simonovic, M., Doncheva, N. T., Morris, J. H., Bork, P., Jensen, L. J. and Mering, C. V. (2019) STRING v11: protein-protein association networks with increased coverage, supporting functional discovery in genome-wide experimental datasets. Nucleic Acids Res. 47, D607-D613

40 Shannon, P., Markiel, A., Ozier, O., Baliga, N. S., Wang, J. T., Ramage, D., Amin, N., Schwikowski, B. and Ideker, T. (2003) Cytoscape: a software environment for integrated models of biomolecular interaction networks. Genome Res. 13, 2498-2504

41 The Gene Ontology, C. (2019) The Gene Ontology Resource: 20 years and still GOing strong. Nucleic Acids Res. 47, D330-D338

42 Yu, G., Wang, L. G., Han, Y. and He, Q. Y. (2012) clusterProfiler: an R package for comparing biological themes among gene clusters. OMICS. 16, 284-287

43 Schmittgen, T. D. and Livak, K. J. (2008) Analyzing real-time PCR data by the comparative C(T) method. Nat Protoc. 3, 1101-1108

44 Hernandez-Diaz, I., Giraldez, T., Arnau, M. R., Smits, V. A., Jaisser, F., Farman, N. and Alvarez de la Rosa, D. (2010) The mineralocorticoid receptor is a constitutive nuclear factor in cardiomyocytes due to hyperactive nuclear localization signals. Endocrinology. 151, 3888-3899 45 Wyatt, A. W., Hussain, A., Amann, K., Klingel, K., Kandolf, R., Artunc, F., Grahammer, F., Huang, D. Y., Vallon, V., Kuhl, D. and Lang, F. (2006) DOCA-induced phosphorylation of glycogen synthase kinase 3beta. Cell Physiol Biochem. 17, 137-144

46 Vallon, V., Wyatt, A. W., Klingel, K., Huang, D. Y., Hussain, A., Berchtold, S., Friedrich, B., Grahammer, F., Belaiba, R. S., Gorlach, A., Wulff, P., Daut, J., Dalton, N. D., Ross, J., Jr., Flogel, U., 
Schrader, J., Osswald, H., Kandolf, R., Kuhl, D. and Lang, F. (2006) SGK1-dependent cardiac CTGF formation and fibrosis following DOCA treatment. J Mol Med. 84, 396-404

47 Han, K. H., Kang, Y. S., Han, S. Y., Jee, Y. H., Lee, M. H., Han, J. Y., Kim, H. K., Kim, Y. S. and Cha, D. R. (2006) Spironolactone ameliorates renal injury and connective tissue growth factor expression in type II diabetic rats. Kidney Int. 70, 111-120

48 Christensen, B. M., Perrier, R., Wang, Q., Zuber, A. M., Maillard, M., Mordasini, D., Malsure, S., Ronzaud, C., Stehle, J. C., Rossier, B. C. and Hummler, E. (2010) Sodium and potassium balance depends on alphaENaC expression in connecting tubule. J Am Soc Nephrol. 21, 1942-1951

49 Schmidt-Ott, K. M., Mori, K., Li, J. Y., Kalandadze, A., Cohen, D. J., Devarajan, P. and Barasch, J. (2007) Dual action of neutrophil gelatinase-associated lipocalin. J Am Soc Nephrol. 18, $407-413$

50 Eriksen, B. O., Stefansson, V. T. N., Jenssen, T. G., Mathisen, U. D., Schei, J., Solbu, M. D., Wilsgaard, T. and Melsom, T. (2016) Elevated blood pressure is not associated with accelerated glomerular filtration rate decline in the general non-diabetic middle-aged population. Kidney Int. 90, 404-410

51 Hoy, W. E., Bertram, J. F., Denton, R. D., Zimanyi, M., Samuel, T. and Hughson, M. D. (2008) Nephron number, glomerular volume, renal disease and hypertension. Curr Opin Nephrol Hypertens. 17, 258-265

52 Sanchez, O. A., Ferrara, L. K., Rein, S., Berglund, D., Matas, A. J. and Ibrahim, H. N. (2018) Hypertension after kidney donation: Incidence, predictors, and correlates. Am J Transplant. 18, 25342543

53 Terada, Y., Kuwana, H., Kobayashi, T., Okado, T., Suzuki, N., Yoshimoto, T., Hirata, Y. and Sasaki, S. (2008) Aldosterone-stimulated SGK1 activity mediates profibrotic signaling in the mesangium. J Am Soc Nephrol. 19, 298-309

54 Lijnen, P. J., Petrov, V. V. and Fagard, R. H. (2003) Association between transforming growth factor-beta and hypertension. Am J Hypertens. 16, 604-611

55 Murphy, M., Godson, C., Cannon, S., Kato, S., Mackenzie, H. S., Martin, F. and Brady, H. R. (1999) Suppression subtractive hybridization identifies high glucose levels as a stimulus for expression of connective tissue growth factor and other genes in human mesangial cells. J Biol Chem. 274, $5830-5834$

56 Lang, F., Klingel, K., Wagner, C. A., Stegen, C., Warntges, S., Friedrich, B., Lanzendorfer, M., Melzig, J., Moschen, I., Steuer, S., Waldegger, S., Sauter, M., Paulmichl, M., Gerke, V., Risler, T., Gamba, G., Capasso, G., Kandolf, R., Hebert, S. C., Massry, S. G. and Broer, S. (2000) Deranged transcriptional regulation of cell-volume-sensitive kinase hSGK in diabetic nephropathy. Proc Natl Acad Sci U S A. 97, 8157-8162 
Erdjument-Bromage, H., Tempst, P. and Massague, J. (2009) Ubiquitin ligase Nedd4L targets activated Smad2/3 to limit TGF-beta signaling. Mol Cell. 36, 457-468

58 Kamenicky, P., Mazziotti, G., Lombes, M., Giustina, A. and Chanson, P. (2014) Growth hormone, insulin-like growth factor-1, and the kidney: pathophysiological and clinical implications. Endocr Rev. 35, 234-281

59 Lother, A., Furst, D., Bergemann, S., Gilsbach, R., Grahammer, F., Huber, T. B., Hilgendorf, I., Bode, C., Moser, M. and Hein, L. (2016) Deoxycorticosterone Acetate/Salt-Induced Cardiac But Not Renal Injury Is Mediated By Endothelial Mineralocorticoid Receptors Independently From Blood Pressure. Hypertension. 67, 130-138

60 Gonzaga-Jauregui, C., Gamble, C. N., Yuan, B., Penney, S., Jhangiani, S., Muzny, D. M., Gibbs, R. A., Lupski, J. R. and Hecht, J. T. (2015) Mutations in COL27A1 cause Steel syndrome and suggest a founder mutation effect in the Puerto Rican population. Eur J Hum Genet. 23, 342-346 61 Pace, J. M., Corrado, M., Missero, C. and Byers, P. H. (2003) Identification, characterization and expression analysis of a new fibrillar collagen gene, COL27A1. Matrix Biol. 22, 3-14 62 Atkinson, J. M., Pullen, N., Da Silva-Lodge, M., Williams, L. and Johnson, T. S. (2015) Inhibition of Thrombin-Activated Fibrinolysis Inhibitor Increases Survival in Experimental Kidney Fibrosis. J Am Soc Nephrol. 26, 1925-1937

63 Karsdal, M. A., Nielsen, S. H., Leeming, D. J., Langholm, L. L., Nielsen, M. J., ManonJensen, T., Siebuhr, A., Gudmann, N. S., Ronnow, S., Sand, J. M., Daniels, S. J., Mortensen, J. H. and Schuppan, D. (2017) The good and the bad collagens of fibrosis - Their role in signaling and organ function. Adv Drug Deliv Rev. 121, 43-56

64 Merline, R., Lazaroski, S., Babelova, A., Tsalastra-Greul, W., Pfeilschifter, J., Schluter, K. D., Gunther, A., Iozzo, R. V., Schaefer, R. M. and Schaefer, L. (2009) Decorin deficiency in diabetic mice: aggravation of nephropathy due to overexpression of profibrotic factors, enhanced apoptosis and mononuclear cell infiltration. J Physiol Pharmacol. 60 Suppl 4, 5-13

65 Ferdous, Z., Wei, V. M., Iozzo, R., Hook, M. and Grande-Allen, K. J. (2007) Decorintransforming growth factor- interaction regulates matrix organization and mechanical characteristics of three-dimensional collagen matrices. J Biol Chem. 282, 35887-35898

66 Tan, R. J. and Liu, Y. (2012) Matrix metalloproteinases in kidney homeostasis and diseases. Am J Physiol Renal Physiol. 302, F1351-1361

67 Zakiyanov, O., Kalousova, M., Zima, T. and Tesar, V. (2019) Matrix Metalloproteinases in Renal Diseases: A Critical Appraisal. Kidney Blood Press Res. 44, 298-330 68 Regos, E., Abdelfattah, H. H., Reszegi, A., Szilak, L., Werling, K., Szabo, G., Kiss, A., Schaff, Z., Kovalszky, I. and Baghy, K. (2018) Syndecan-1 inhibits early stages of liver fibrogenesis by interfering with TGFbeta1 action and upregulating MMP14. Matrix Biol. 68-69, 474-489 
69 Zigrino, P., Brinckmann, J., Niehoff, A., Lu, Y., Giebeler, N., Eckes, B., Kadler, K. E. and Mauch, C. (2016) Fibroblast-Derived MMP-14 Regulates Collagen Homeostasis in Adult Skin. J Invest Dermatol. 136, 1575-1583

70 Yan, L., Borregaard, N., Kjeldsen, L. and Moses, M. A. (2001) The high molecular weight urinary matrix metalloproteinase (MMP) activity is a complex of gelatinase B/MMP-9 and neutrophil gelatinase-associated lipocalin (NGAL). Modulation of MMP-9 activity by NGAL. J Biol Chem. 276, 37258-37265

71 Chen, W., Yang, A., Jia, J., Popov, Y. V., Schuppan, D. and You, H. (2020) Lysyl oxidase (LOX) family members: rationale and their potential as therapeutic targets for liver fibrosis. Hepatology

72 Cosgrove, D., Dufek, B., Meehan, D. T., Delimont, D., Hartnett, M., Samuelson, G., Gratton, M. A., Phillips, G., MacKenna, D. A. and Bain, G. (2018) Lysyl oxidase like-2 contributes to renal fibrosis in Col4alpha3/Alport mice. Kidney Int. 94, 303-314

73 Xu, X. H., Jia, Y., Zhou, X., Xie, D., Huang, X., Jia, L., Zhou, Q., Zheng, Q., Zhou, X., Wang, K. and Jin, L. P. (2019) Downregulation of lysyl oxidase and lysyl oxidase-like protein 2 suppressed the migration and invasion of trophoblasts by activating the TGF-beta/collagen pathway in preeclampsia. Exp Mol Med. 51, 1-12

74 Nakasaki, M., Hwang, Y., Xie, Y., Kataria, S., Gund, R., Hajam, E. Y., Samuel, R., George, R., Danda, D., M, J. P., Nakamura, T., Shen, Z., Briggs, S., Varghese, S. and Jamora, C. (2015) The matrix protein Fibulin-5 is at the interface of tissue stiffness and inflammation in fibrosis. Nat Commun. 6, 8574

75 Taguchi, T. and Razzaque, M. S. (2007) The collagen-specific molecular chaperone HSP47: is there a role in fibrosis? Trends Mol Med. 13, 45-53

76 Shao, Z., Nishimura, T., Leung, L. L. and Morser, J. (2015) Carboxypeptidase B2 deficiency reveals opposite effects of complement $\mathrm{C} 3 \mathrm{a}$ and $\mathrm{C} 5 \mathrm{a}$ in a murine polymicrobial sepsis model. $\mathrm{J}$ Thromb Haemost. 13, 1090-1102

77 Yoshida, T., Kato, K., Fujimaki, T., Yokoi, K., Oguri, M., Watanabe, S., Metoki, N., Yoshida, H., Satoh, K., Aoyagi, Y., Nishigaki, Y., Tanaka, M., Nozawa, Y. and Yamada, Y. (2009) Association of a polymorphism of the apolipoprotein $\mathrm{E}$ gene with chronic kidney disease in Japanese individuals with metabolic syndrome. Genomics. 93, 221-226

78 Borel, F., Sun, H., Zieger, M., Cox, A., Cardozo, B., Li, W., Oliveira, G., Davis, A., Gruntman, A., Flotte, T. R., Brodsky, M. H., Hoffman, A. M., Elmallah, M. K. and Mueller, C. (2018) Editing out five Serpinal paralogs to create a mouse model of genetic emphysema. Proc Natl Acad Sci U S A. 115, 2788-2793

79 Fischer, H. P., Ortiz-Pallardo, M. E., Ko, Y., Esch, C. and Zhou, H. (2000) Chronic liver disease in heterozygous alpha1-antitrypsin deficiency PiZ. J Hepatol. 33, 883-892 
80 Maicas, N., van der Vlag, J., Bublitz, J., Florquin, S., Bakker-van Bebber, M., Dinarello, C. A., Verweij, V., Masereeuw, R., Joosten, L. A. and Hilbrands, L. B. (2017) Human Alpha-1Antitrypsin (hAAT) therapy reduces renal dysfunction and acute tubular necrosis in a murine model of bilateral kidney ischemia-reperfusion injury. PLoS One. 12, e0168981

81 Latouche, C., Sainte-Marie, Y., Steenman, M., Castro Chaves, P., Naray-Fejes-Toth, A., Fejes-Toth, G., Farman, N. and Jaisser, F. (2010) Molecular signature of mineralocorticoid receptor signaling in cardiomyocytes: from cultured cells to mouse heart. Endocrinology. 151, 4467-4476 82 Sanchez-Navarro, A., Mejia-Vilet, J. M., Perez-Villalva, R., Carrillo-Perez, D. L., MarquinaCastillo, B., Gamba, G. and Bobadilla, N. A. (2019) SerpinA3 in the Early Recognition of Acute Kidney Injury to Chronic Kidney Disease (CKD) transition in the rat and its Potentiality in the Recognition of Patients with CKD. Sci Rep. 9, 10350

83 Eksteen, B., Miles, A., Curbishley, S. M., Tselepis, C., Grant, A. J., Walker, L. S. and Adams, D. H. (2006) Epithelial inflammation is associated with CCL28 production and the recruitment of regulatory T cells expressing CCR10. J Immunol. 177, 593-603

84 Cippa, P. E., Liu, J., Sun, B., Kumar, S., Naesens, M. and McMahon, A. P. (2019) A late B lymphocyte action in dysfunctional tissue repair following kidney injury and transplantation. Nat Commun. 10, 1157

85 Mattson, D. L. (2014) Infiltrating immune cells in the kidney in salt-sensitive hypertension and renal injury. Am J Physiol Renal Physiol. 307, F499-508

86 Bubb, K. J., Khambata, R. S. and Ahluwalia, A. (2012) Sexual dimorphism in rodent models of hypertension and atherosclerosis. Br J Pharmacol. 167, 298-312

87 Karatas, A., Hegner, B., de Windt, L. J., Luft, F. C., Schubert, C., Gross, V., Akashi, Y. J., Gurgen, D., Kintscher, U., da Costa Goncalves, A. C., Regitz-Zagrosek, V. and Dragun, D. (2008) Deoxycorticosterone acetate-salt mice exhibit blood pressure-independent sexual dimorphism.

Hypertension. 51, 1177-1183 


\section{ACKNOWLEDGEMENTS}

We would like to thank Dr. Frederic Jaisser and Dr. Pablo Martín-Vasallo for critical reading of the manuscript, and Dr. Natalia Lopez-Andres and Dr. Eduardo Salido for expert advice on assessing kidney fibrosis. This study was funded by grant BFU2016-78374-R from Ministerio de Ciencia, Universidades e Innovación (MICINN, Spain) and European Union FP7 COST ADMIRE Network (BM1301). S.V.-G. is supported by Programa Agustin de Betancourt (Cabildo de Tenerife, Spain). E.P. is a researcher of the Ramón y Cajal Program (MICINN, RYC-2014-16573) and the Red de Investigación Renal (REDinREN, Spain, RD16/0009/0031).

\section{AUTHOR CONTRIBUTIONS}

C.S.-R.: conceptualization, methodology, validation, formal analysis, investigation, writing, visualization.

S.V.-G.: methodology, validation, formal analysis, investigation, writing.

A.G.: validation, formal analysis, visualization.

A.V.-M.: validation, formal analysis, investigation.

A.E.R.-R.: methodology, investigation.

S.L.-L.: methodology, investigation, formal analysis.

G.H.: methodology, investigation, writing

J.F.N.-G.: conceptualization, formal analysis, writing.

E.P.: formal analysis, writing.

O.K.: validation, formal analysis, writing, visualization.

D.A.d.1.R.: conceptualization, formal analysis, writing, visualization, supervision, project administration, funding acquisition.

Competing financial interests: The authors declare no competing financial interests. 


\section{FIGURE LEGENDS}

\section{Figure 1. Transgenic expression of constitutively active SGK1 in the kidney and increased} phosphorylation of SGK1 downstream target GSK-3. A, Schematic representation of the 3' end of the modified $S g k l$ gene, including three copies of an HA tag (3x HA) and point mutation S422D, which renders the kinase constitutively active (asterisk). Arrows indicate oligonucleotides used to simultaneously detect endogenous and transgenic SGK1 by RT-PCR. B, Agarose gel electrophoresis analysis of RT-PCR products obtained from wild type (WT) or transgenic (Tg) kidney cortex cDNA using the oligonucleotide pair shown in panel A. M, molecular mass makers (values in base pairs). Arrow indicates the additional PCR product due to the presence of the transgene. $\mathbf{C}$, Relative SGK1 mRNA abundance in the indicated WT and Tg.sgk1 mice experimental groups (DS, mice treated with DOCA $/ \mathrm{NaCl})$. Bars represent average $\pm \mathrm{SE}(\mathrm{N}=6-8)$ normalized to GAPDH expression. One-way ANOVA followed by Tukey's multiple comparison test $\left(^{*}, \mathrm{p}<0.05\right)$. D, Representative western blots of kidney lysates from WT and Tg mice probed with anti-GSK-3 $\beta$ or anti-phospho-GSK-3 $\alpha / \beta$ (pGSK$3 \alpha / \beta)$ antibodies. Lines indicate molecular mass marker migration (values in $\mathrm{kDa}$ ). E, Relative abundance of pGSK-3 $\alpha / \beta$ in WT and Tg.sgk1 kidney lysates. Bars represent average $\pm \mathrm{SE}(\mathrm{N}=6)$ pGSK3 $\beta /$ GSK3 $\beta$ normalized to WT. * ${ }^{*}$ p $<0.05$, unpaired t test.

Figure 2. DOCA/NaCl-induced increase in systolic blood pressure is more pronounced in NPX Tg.sgk1 mice. A, Two-kidney animals left untreated or treated with DOCA/ $\mathrm{NaCl}$ (DS) for 6 weeks. B, NPX animals left untreated or treated with DOCA/ $\mathrm{NaCl}$ (NDS) for 6 weeks. Points represent average systolic blood pressure (SBP) in individual animals. Bars represent mean $\pm \mathrm{SD}(\mathrm{N}=6-8)$. Oneway ANOVA followed by Sidak's multiple comparison test for the indicated pairs of columns. ${ }^{*}, \mathrm{p}<$ 0.05 ; ns, no significant difference.

\section{Figure 3. Increased SGK1 activity exacerbates albuminuria after NPX and DOCA/NaCl}

challenge. A, Urinary albumin/creatinine ratio ( $\mathrm{UACR}$ ). Data points represent measurements from individual mice. Bars represent experimental group average $\pm \mathrm{SD}(\mathrm{N}=8-12)$. Measurements were compared using one-way ANOVA followed by Tukey's multiple comparison test $(*, \mathrm{p}<0.05$; **, $\mathrm{p}<0.01 ; * * *, \mathrm{p}<0.001 ; \mathrm{ns}$, no significant difference). B, Glomerular filtration rate (GFR) was measured using the iohexol plasma clearance method in control wild type or transgenic animals (WT and Tg, $\mathrm{N}=10$ ), nephrectomized animals (WT-NPX and Tg-NPX, N = 5) and in animals after 5 weeks of NDS treatment $(\mathrm{N}=4)$. Bars represent experimental group average $\pm \mathrm{SD}$. Measurements were compared using one-way ANOVA followed by Tukey's multiple comparison test $\left({ }^{*}, \mathrm{p}<0.05 ; * *\right.$, $\mathrm{p}<0.01 ; \mathrm{ns}$, no significant difference).

Figure 4. Tg.sgk1 display glomerular hypertrophy and increased fibrosis. A, Frequency distribution analysis of glomerular area in the indicated experimental groups. Insets show representative images of individual glomeruli from 3- $\mu \mathrm{m}$ tissue sections stained with Sirius red (scale bar $=30 \mu \mathrm{m})$. Plot bars represent percentage of glomeruli in each diameter class $(n=46)$. Curves 
represent Gaussian fitting of the data. Medians of area distribution are indicated by dashed lines. Mann-Whitney test $(* * *, p<0.001)$. B, Representative images of kidney cortex obtained from the indicated experimental groups and stained with Sirius red. C, Quantification of Sirius red-positive area in glomeruli, interstitial and perivascular regions. Each point represents average percentage positive area obtained from five independent fields for one animal. Bars represent experimental group average $\pm \mathrm{SD}\left(\mathrm{N}=8\right.$-12 animals). One-way ANOVA followed by Tukey's multiple comparison test $\left({ }^{*}, \mathrm{p}<\right.$ $0.05 ; * *, p<0.01)$. D, Relative mRNA levels of the indicated fibrosis markers in WT and Tg.sgk1 mice experimental groups. Bars represent average $\pm \mathrm{SD}(\mathrm{N}=5-6)$ mRNA abundance values normalized to GAPDH expression. One-way ANOVA followed by Tukey's multiple comparison test $(*, p<0.05$; **, $\mathrm{p}<0.01 ; * * *, \mathrm{p}<0.001)$.

Figure 5. Limited tubular injury in NDS Tg.sgk1 mice. A, Fractional excretion of $\mathrm{Na}^{+}\left(\mathrm{FE}_{\mathrm{Na}}\right)$, expressed as \%. Individual points represent values from each animal $(\mathrm{N}=4-5)$. Bars represent average \pm SD. One-way ANOVA followed by Tukey's multiple comparison test. ${ }^{* *}, \mathrm{p}<0.01 ; * * *, p<0.001$. B, Relative expression of tubular injury markers in the indicated WT and Tg.sgk1 mice groups. Bars represent average $\pm \mathrm{SD}(\mathrm{N}=5-6) \mathrm{mRNA}$ abundance values normalized to GAPDH expression. Oneway ANOVA followed by Tukey's multiple comparison test. *, p $<0.05 ; * *, p<0.01 ; * * *, p<0.001$.

Figure 6. The differentially expressed genes obtained from the microarray experiment. A, Volcano plot showing the differentially upregulated and downregulated genes along with those not significantly changed. P stands for FDR $<0.15$ while the logarithmically (base 2) transformed fold change $(\log 2 \mathrm{FC})$ is greater than 1 or less than -1 . Colours indicate genes that pass the thresholds given by only $\mathrm{P}$, only $\log 2 \mathrm{FC}$ or both. B, Heatmap of the differentially expressed genes with an adjusted $\mathrm{p}$ value threshold of $\mathrm{FDR}<0.15$. Upregulation and downregulation are represented by a spectrum of red and blue, respectively. $\mathbf{C}$, Gene network of differentially expressed genes between the groups. Nodes represent genes whose log2FC values are indicated by colours (pink-blue; up-down, respectively) while the edges that connect the nodes refer to the interactions specified by STRING database.

Figure 7. Functional annotation of differentially expressed genes in Tg.sgk1 after NDS. Gene Ontology (GO) term enrichment analysis for up- and down-regulated genes (FDR cut-off value $<0.3$ ). Adjusted $\mathrm{p}$ values are indicated using the color scale shown in the figure. Circle diameter is proportional to the number of genes in each GO category.

Figure 8. Validation of transcripts predicted by microarray analysis to be differentially regulated in NDS WT or Tg.sgk1 mice. A, Expression of the indicated genes was assessed by quantitative real-time PCR in the four groups used in this study (WT-NPX, Tg-NPX, WT-NDS and Tg-NDS). Bars represent average $\pm \mathrm{SE}(\mathrm{N}=6)$. Statistical analysis was performed by one-way ANOVA followed by Tukey's Multiple Comparison Test $(*, p<0.05 ; * * p<0.01 ; * * *, p<0.001)$. B, Representative micrographs of cultured MEFs obtained from WT or Tg.sgk1 embryos. Scale bar, 200 $\mu \mathrm{m}$. C, Expression of newly identified differentially expressed genes in MEFs from WT or transgenic animals. Bars represent average $\pm \mathrm{SE}(\mathrm{N}=6)$. Transcripts below qPCR detection level are indicated by 
bioRxiv preprint doi: https://doi.org/10.1101/2020.07.08.191874. this version posted July 9, 2020. The copyright holder for this preprint (which was not certified by peer review) is the author/funder. It is made available under a CC-BY 4.0 International license.

"nd" (non-detected). Statistical analysis was performed by one-way ANOVA followed by Tukey's Multiple Comparison Test $(* * \mathrm{p}<0.01$; ns, no significant difference). 
Table 1. Primers and quantitative RT-PCR probesets used in this study. In the case of TaqMan ${ }^{\circledR}$ probe sets, catalog numbers are indicated. Gapdh, glyceraldehyde-3-phosphate dehydrogenase; Acta2, smooth muscle actin, alpha 2; Ctgf, connective tissue growth factor; Collal, collagen type I, alpha 1; Col4al, collagen type IV, alpha 1; Fn1, fibronectin 1; Kim-1, kidney injury molecule 1 (Havcr 1); Lcn2, lipocalin-2 (NGAL); Ccl2, chemokine (C-C motif) ligand 2 (MCP-1); Tgfbl, transforming growth factor, beta 1; Col27al, collagen type XXVII, alpha 1; Lyplall, lysophospholipase-like 1; Cpb2, carboxypeptidase B2; Serpina3b, serine (or cysteine) peptidase inhibitor, clade A, member 3B; Ccl28, chemokine (C-C motif) ligand 28; Adamtsl2, ADAMTS-like 2.

\begin{tabular}{|c|c|c|c|}
\hline Gene & Forward & Reverse & Use \\
\hline Gapdh & ATGGGAAGCTGGTCATCAAC & GTGGTTCACACCCATCACAA & qPCR \\
\hline $\operatorname{Sgkl}$ & GGAAGCAGCAGAAGCCTTCCTCGG & GACTGCCAAGCTTCCGGTGTGC & RT-PCR \\
\hline Sgkl & CGGTTTCACTGCTCCCCTCAG & GCGATGAGAATCGCTACCATT & qPCR \\
\hline Ctgf & CTGCCTACCGACTGGAAGACACATT & TCTCCAGTCTGCAGAAGGTATTGTC & qPCR \\
\hline Collal & TGCCGTGACCTCAAGATGTG & CACAAGCGTGCTGTAGGTGA & qPCR \\
\hline Col4a1 & CAAGCATAGTGGTCCGAGTC & AGGCAGGTCAAGTTCTAGCG & qPCR \\
\hline Fn1 & ACGATGGAAGACCTACGGATGTA & TCAGCTTGCACATCTAACGGCAT & $\mathrm{qPCR}$ \\
\hline Acta 2 & TGCTATGTCGCTCTGGACTTTGA & ATGAAAGATGGCTGGAAGAGG GTC & $\mathrm{qPCR}$ \\
\hline Kim-1 & ATGAATCAGATTCAAGTCTTC & TCTGGTTTGTGAGTCCATGTG & qPCR \\
\hline Len 2 & GGACCAGGGCTGTCGCTACT & GGTGGCCACTTGCACATTGT & qPCR \\
\hline $\mathrm{Ccl} 2$ & GTCACCAAGCTCAAGAGAGA & GTGGAAAAGGTAGTGGATGC & $\mathrm{qPCR}$ \\
\hline \multicolumn{4}{|c|}{ Probe set } \\
\hline Gapdh & \multicolumn{2}{|c|}{ TaqMan® Mm99999915_g1 (Thermo Fisher) } & qPCR \\
\hline $\operatorname{Tg} f b l$ & \multicolumn{2}{|c|}{ TaqMan $®$ Mm 01178820_m1 (Thermo Fisher) } & $\mathrm{qPCR}$ \\
\hline Col27al & \multicolumn{2}{|c|}{ TaqMan® Mm01267526_m1 (Thermo Fisher) } & $\mathrm{qPCR}$ \\
\hline Lyplal1 & \multicolumn{2}{|c|}{ TaqMan® Mm00525055_m1 (Thermo Fisher) } & qPCR \\
\hline$C p b 2$ & \multicolumn{2}{|c|}{ TaqMan® Mm00490698_m1 (Thermo Fisher) } & qPCR \\
\hline Serpina $3 b$ & \multicolumn{2}{|c|}{ TaqMan® Mm00557205_m1 (Thermo Fisher) } & $\mathrm{qPCR}$ \\
\hline Ccl28 & \multicolumn{2}{|c|}{ TaqMan® Mm00445039_m1 (Thermo Fisher) } & $\mathrm{qPCR}$ \\
\hline Adamtsl2 & \multicolumn{2}{|c|}{ TaqMan ${ }^{\circledR}$ Mm01326794_ml (Thermo Fisher) } & $\mathrm{qPCR}$ \\
\hline
\end{tabular}


bioRxiv preprint doi: https://doi.org/10.1101/2020.07.08.191874. this version posted July 9, 2020. The copyright holder for this preprint (which was not certified by peer review) is the author/funder. It is made available under a CC-BY 4.0 International license.

Table 2. General characteristics of nephrectomized (NPX) WT and Tg.sgk1 mice treated or not with DOCA/NaCl (NDS groups). Results are expressed as average \pm SD (n, number of animals). Statistical significance was analysed using one-way ANOVA followed by Tukey's multiple comparison test. There were no significant differences between genotypes in NPX or NDS groups. ${ }^{*}, \mathrm{p}<0.05$ compared to the same genotype.

\begin{tabular}{|c|c|c|c|c|}
\hline \multirow{2}{*}{ Variable (units) } & \multicolumn{2}{|c|}{ NPX } & \multicolumn{2}{|c|}{ NDS } \\
\hline & WT & Tg.sgk1 & WT & Tg.sgk1 \\
\hline Kidney weight $^{\dagger}$ & $7.5 \pm 0.1 ; n=10$ & $7.9 \pm 0.2 ; n=10$ & $9.8 \pm 0.2 * ; n=12$ & $10.0 \pm 0.3^{*} ; \mathrm{n}=10$ \\
\hline Aldosterone (nM) & $1.51 \pm 0.59 ; n=4$ & $0.77 \pm 0.36 ; n=4$ & $1.15 \pm 0.21 * ; n=5$ & $0.66 \pm 0.25 ; n=5$ \\
\hline Corticosterone (nM) & $110 \pm 17 ; n=4$ & $55 \pm 16 ; n=4$ & $141 \pm 52 ; n=5$ & $85 \pm 30 ; n=5$ \\
\hline Plasma $\mathrm{Na}^{+}(\mathrm{mM})$ & $151.5 \pm 1.9 ; n=5$ & $150.0 \pm 0.9 ; n=5$ & $152.0 \pm 1.3 ; \mathrm{n}=6$ & $150.8 \pm 2.4 ; n=5$ \\
\hline Plasma K $\mathrm{K}^{+}(\mathrm{mM})$ & $7.4 \pm 0.1 ; n=5$ & $6.6 \pm 0.3 ; n=5$ & $6.8 \pm 0.3 ; n=6$ & $7.0 \pm 0.4 ; n=5$ \\
\hline Plasma $\mathrm{Cl}^{-}(\mathrm{mM})$ & $105.0 \pm 1.1 ; \mathrm{n}=5$ & $102.3 \pm 0.6, n=5$ & $105.0 \pm 0.8 ; n=6$ & $102.8 \pm 1.7, n=5$ \\
\hline Urine $\mathrm{Na}^{+}(\mathrm{mM})$ & $71.2 \pm 4.4 ; n=5$ & $74.0 \pm 13.3 ; n=5$ & $273.0 \pm 15.7^{*} ; n=6$ & $260.0 \pm 27.7^{*} ; n=5$ \\
\hline Urine $\mathrm{K}^{+}(\mathrm{mM})$ & $235.1 \pm 17.2 ; n=5$ & $209.7 \pm 30.7 ; n=5$ & $27.8 \pm 5.0 * ; \mathrm{n}=6$ & $33.0 \pm 7.5^{*} ; \mathrm{n}=5$ \\
\hline Urine $\mathrm{Cl}^{-}(\mathrm{mM})$ & $160.6 \pm 17.2 ; n=5$ & $162.6 \pm 26.7 ; n=5$ & $292.3 \pm 17.0^{*} ; \mathrm{n}=6$ & $276.3 \pm 33.3^{*} ; \mathrm{n}=5$ \\
\hline Diuresis $(\mathrm{ml} / 24 \mathrm{~h})$ & $1.33 \pm 0.22 ; \mathrm{n}=5$ & $1.76 \pm 0.46 ; n=5$ & $5.31 \pm 0.22 * ; n=6$ & $5.74 \pm 0.19^{*} ; \mathrm{n}=5$ \\
\hline Water intake $(\mathrm{ml} / 24 \mathrm{~h})$ & $5.74 \pm 0.51 ; n=5$ & $8.42 \pm 1.34 ; n=5$ & $11.4 \pm 0.56^{*} ; n=6$ & $13.5 \pm 2.01 * ; n=5$ \\
\hline
\end{tabular}

†Normalized to body weight x1000 
Fig. 1. Sierra-Ramos et al.

A

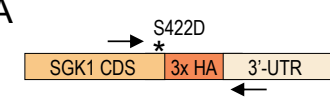

B
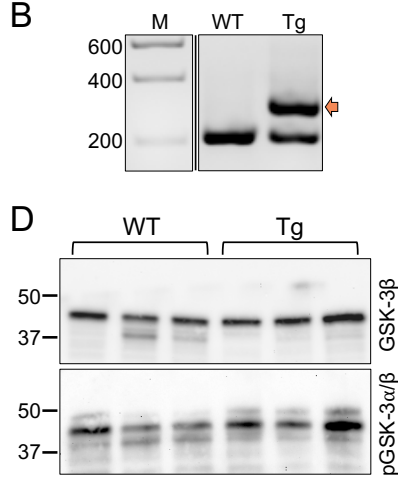

C

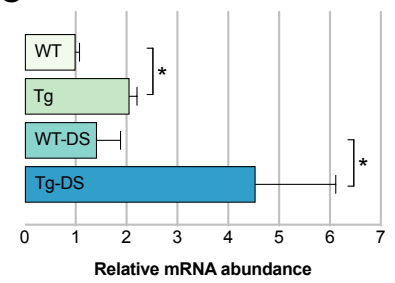

E

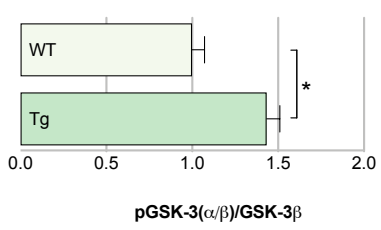


Fig. 2. Sierra-Ramos et al.

A

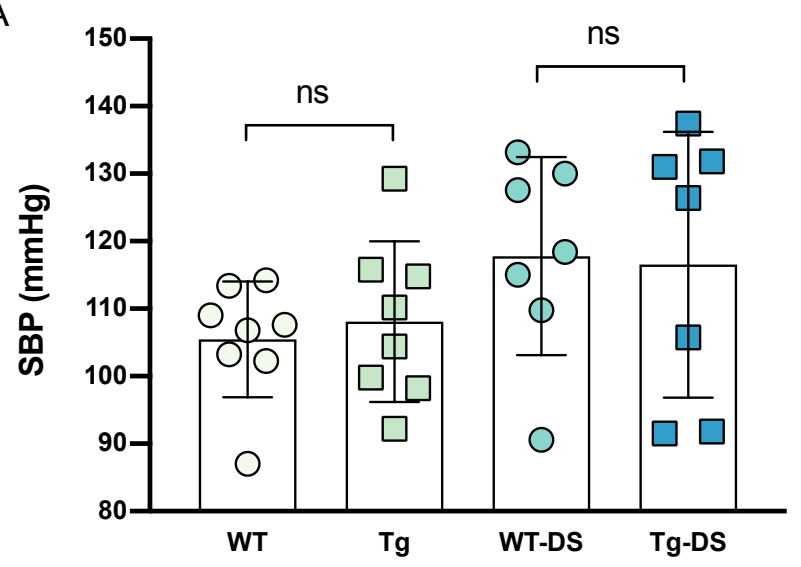

B

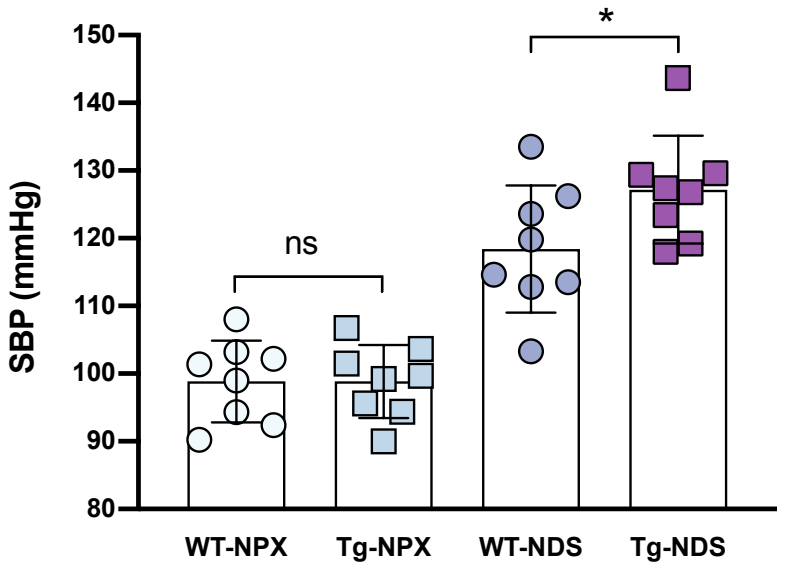


Fig. 3. Sierra-Ramos et al.

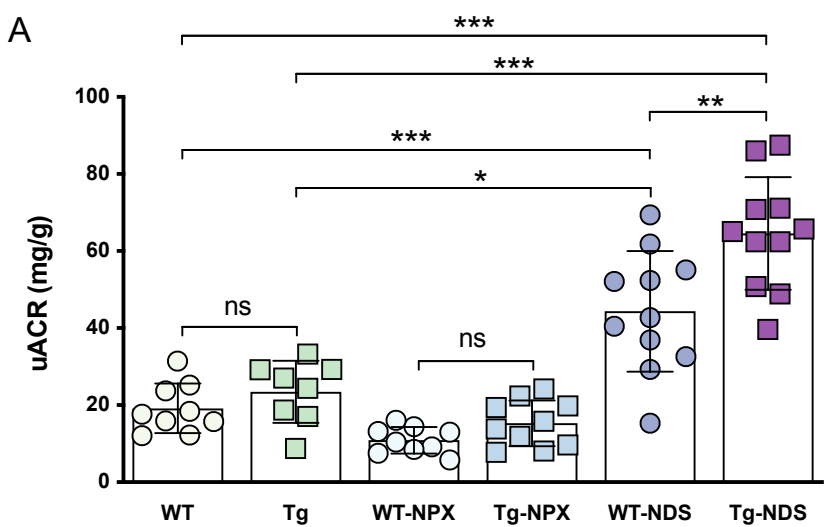

B

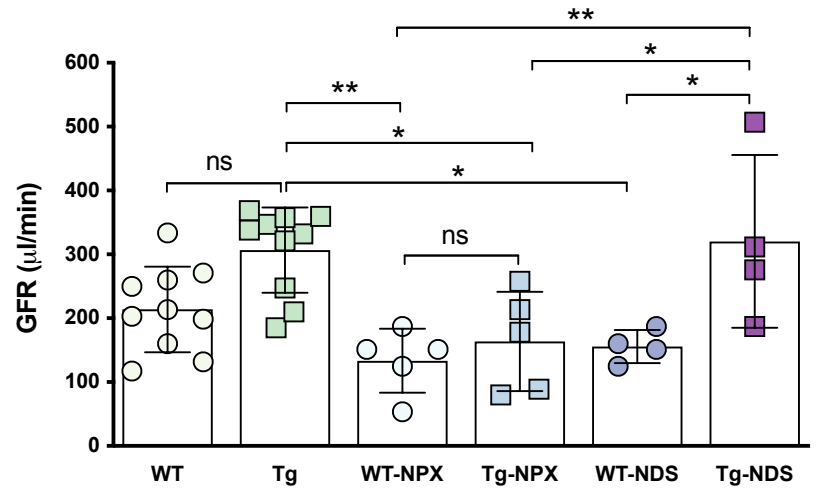


Fig. 4. Sierra-Ramos et al.

A
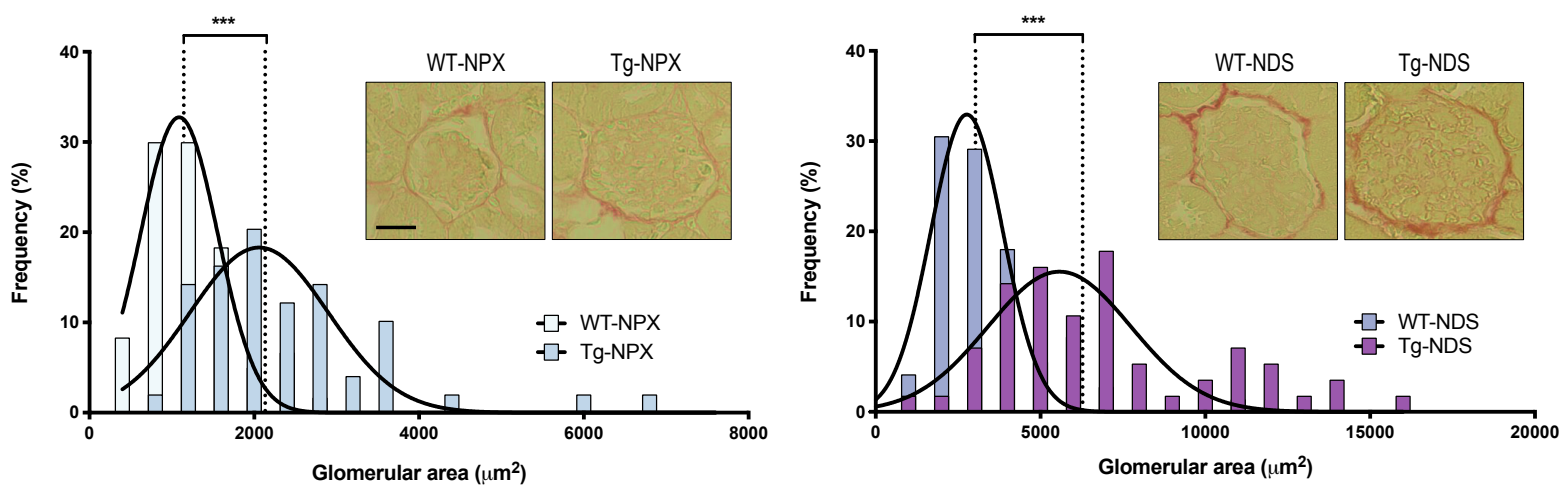

B

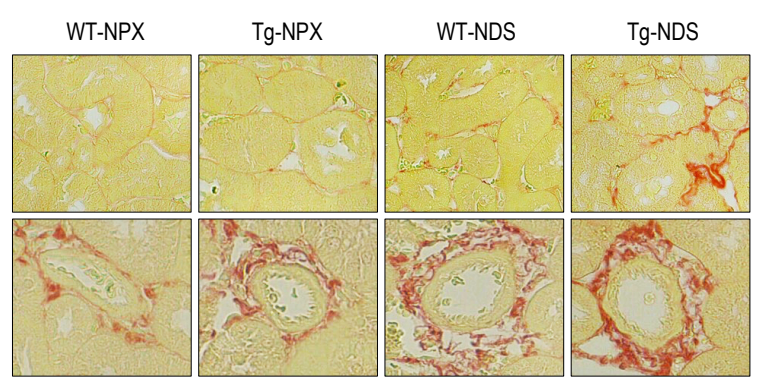

D

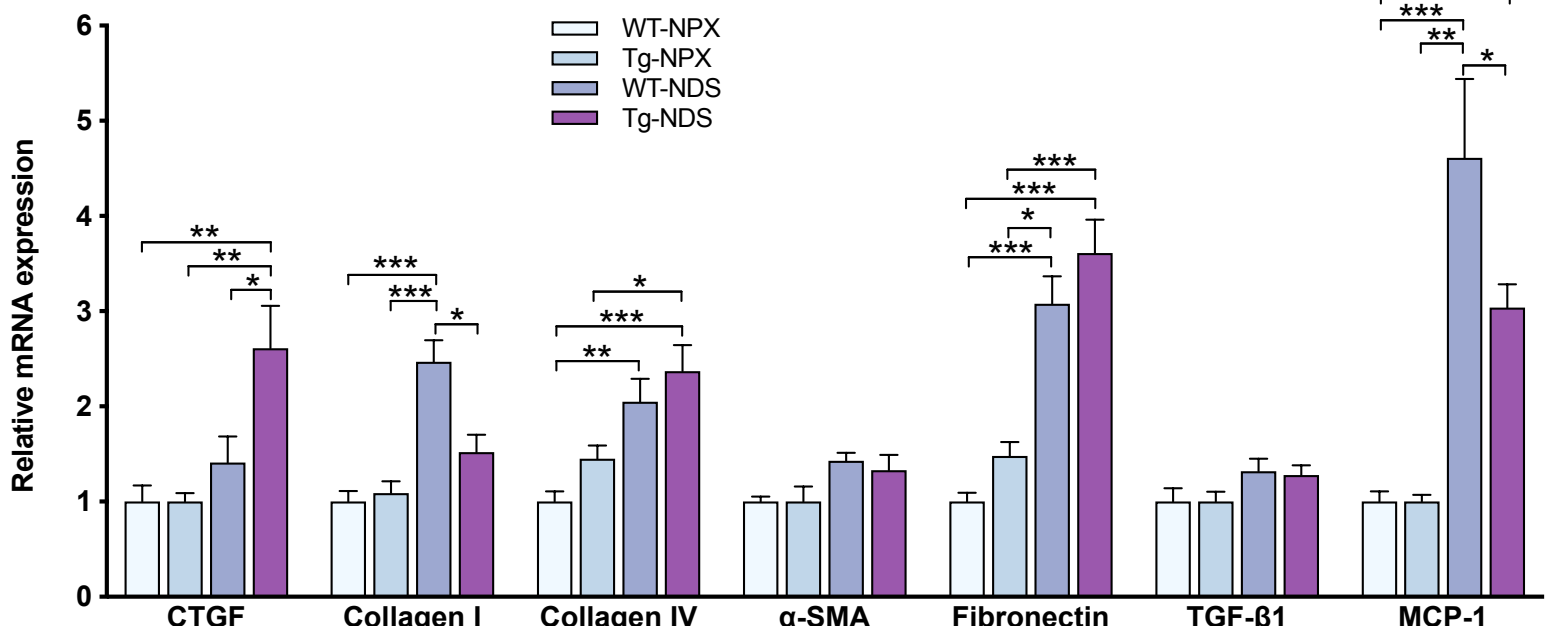

C

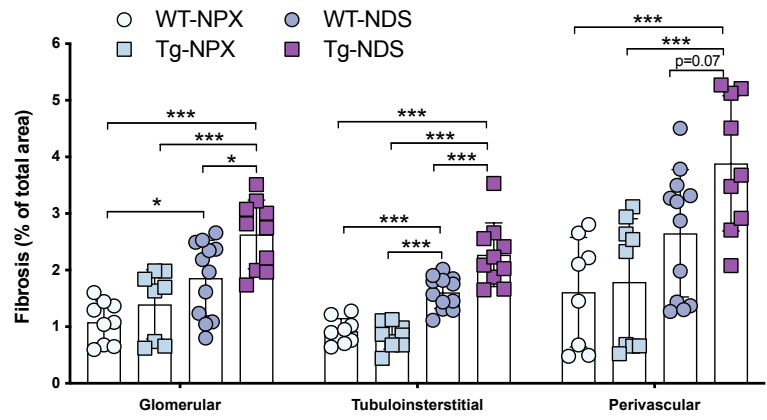

CTGF

Collagen I

Collagen IV $\alpha$-SMA

Fibronectin

TGF- $\beta 1$

MCP-1 
Fig. 5. Sierra-Ramos et al.
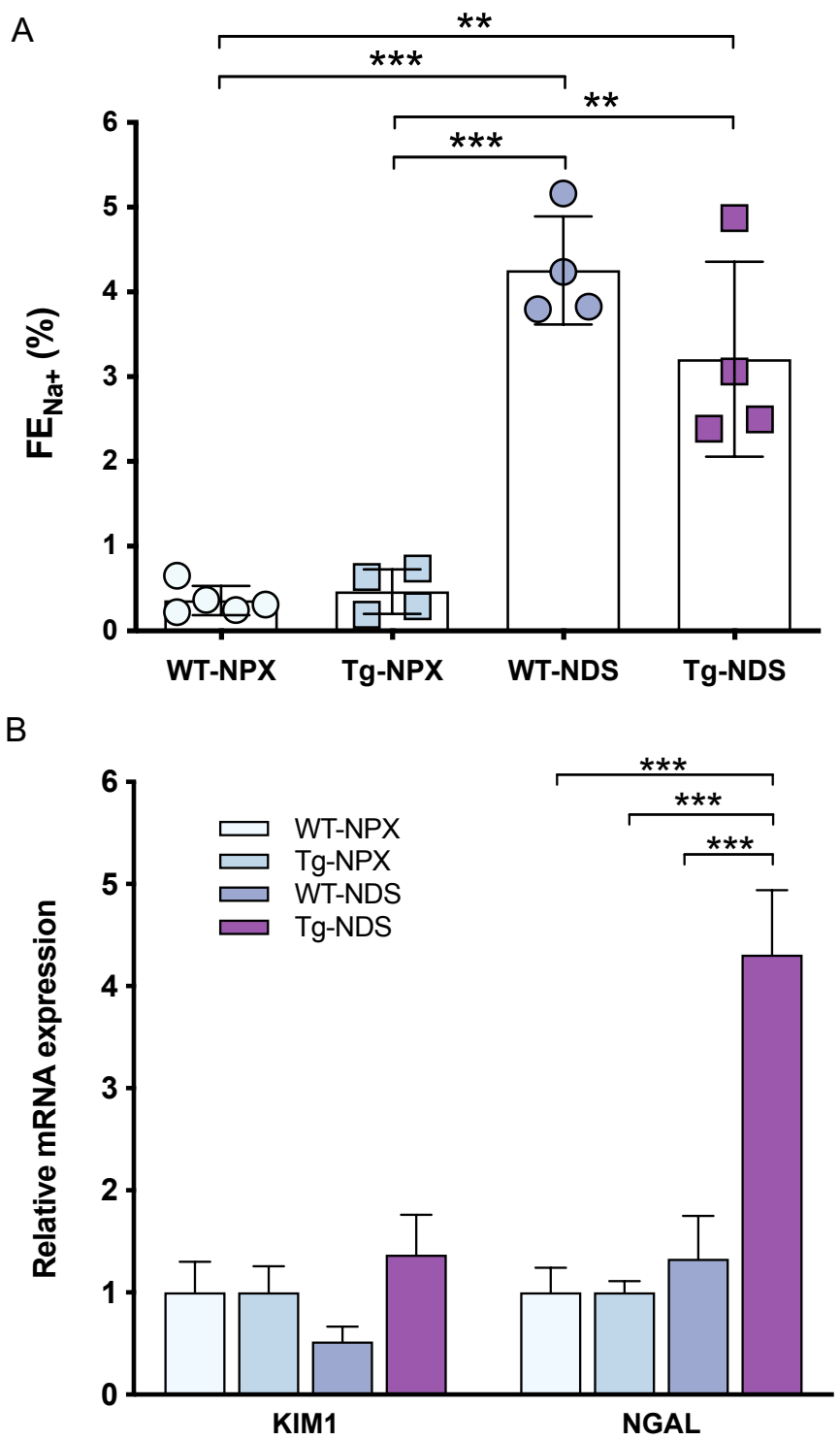
Fig. 6. Sierra-Ramos et al.

A

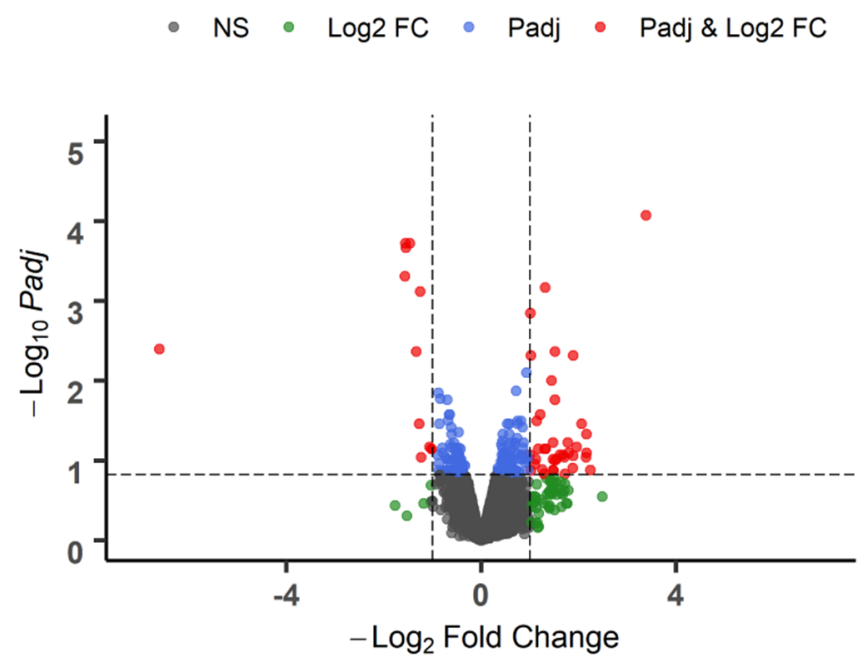

Total $=34472$ variables
B

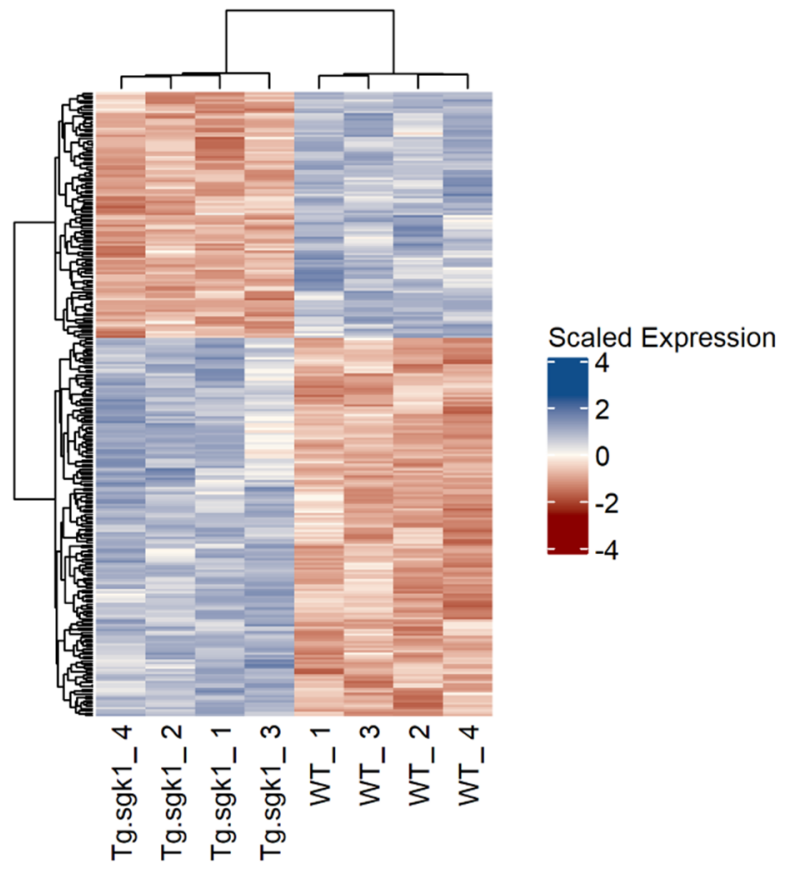

C
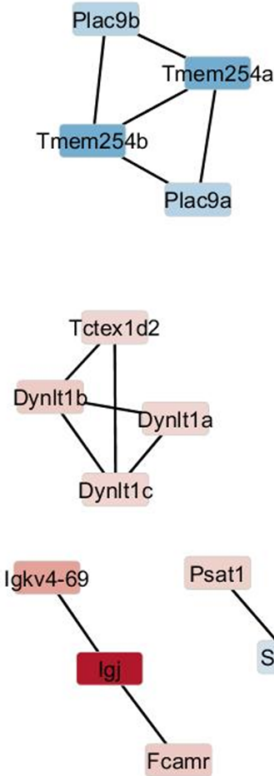
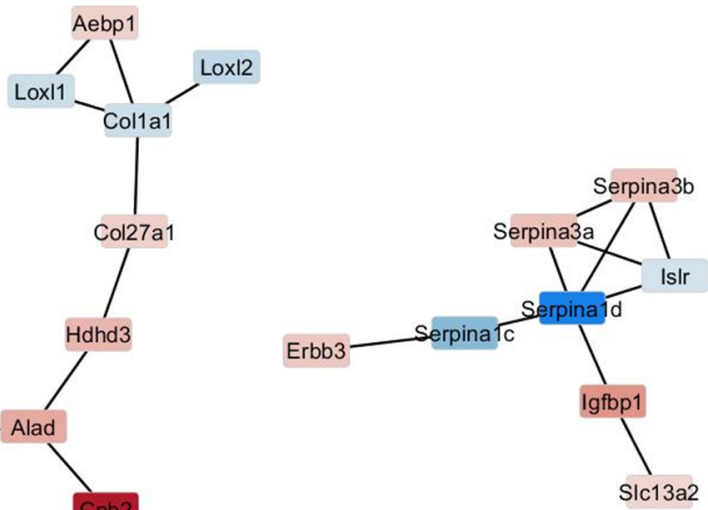

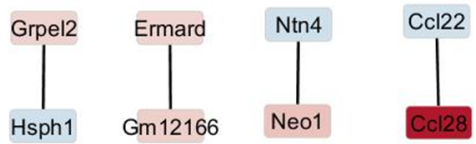


Fig. 7. Sierra-Ramos et al.

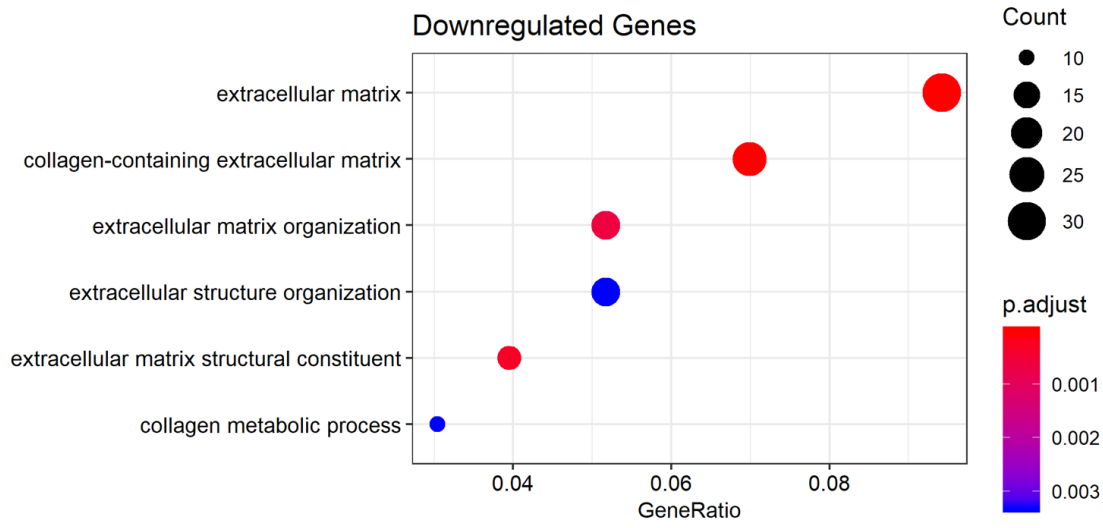

\section{Upregulated Genes}

immune response-regulating signaling pathway immune response-activating signal transduction activation of immune response leukocyte mediated immunity

positive regulation of lymphocyte activation positive regulation of leukocyte activation positive regulation of cell activation immune response-regulating cell surface receptor signaling pathway lymphocyte mediated immunity adaptive immune response based on somatic recombination... antigen binding regulation of $B$ cell activation immune response-activating cell surface receptor signaling pathway production of molecular mediator of immune response defense response to bacterium $B$ cell activation

positive regulation of $\mathrm{B}$ cell activation immunoglobulin production antigen receptor-mediated signaling pathway
humoral immune response

immunoglobulin complex, circulating immunoglobulin complex

immunoglobulin receptor binding

$B$ cell receptor signaling pathway protein activation cascade

immunoglobulin mediated immune response $B$ cell mediated immunity cell recognition phagocytosis, recognition complement activation, classical pathway humoral immune response mediated by circulating immunoglobulin complement activation phagocytosis, engulfment plasma membrane invagination membrane invagination fatty acid metabolic process organelle inner membrane cofactor metabolic process mitochondrial inner membrane coenzyme binding lipid catabolic process alcohol metabolic process small molecule catabolic process acylglycerol metabolic process neutral lipid metabolic process triglyceride metabolic process secondary alcohol metabolic process quinone metabolic process -

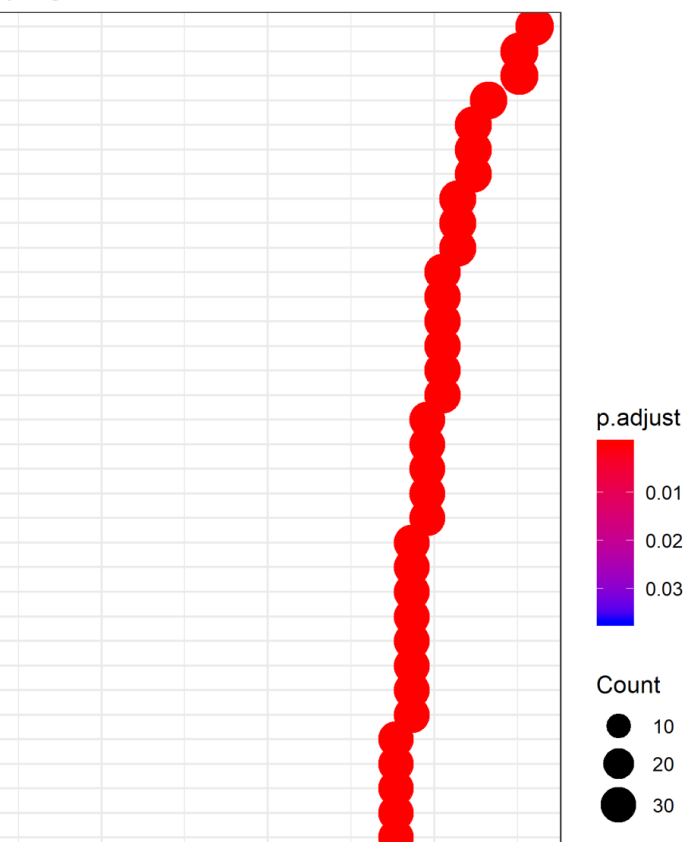


Fig. 8. Sierra-Ramos et al.
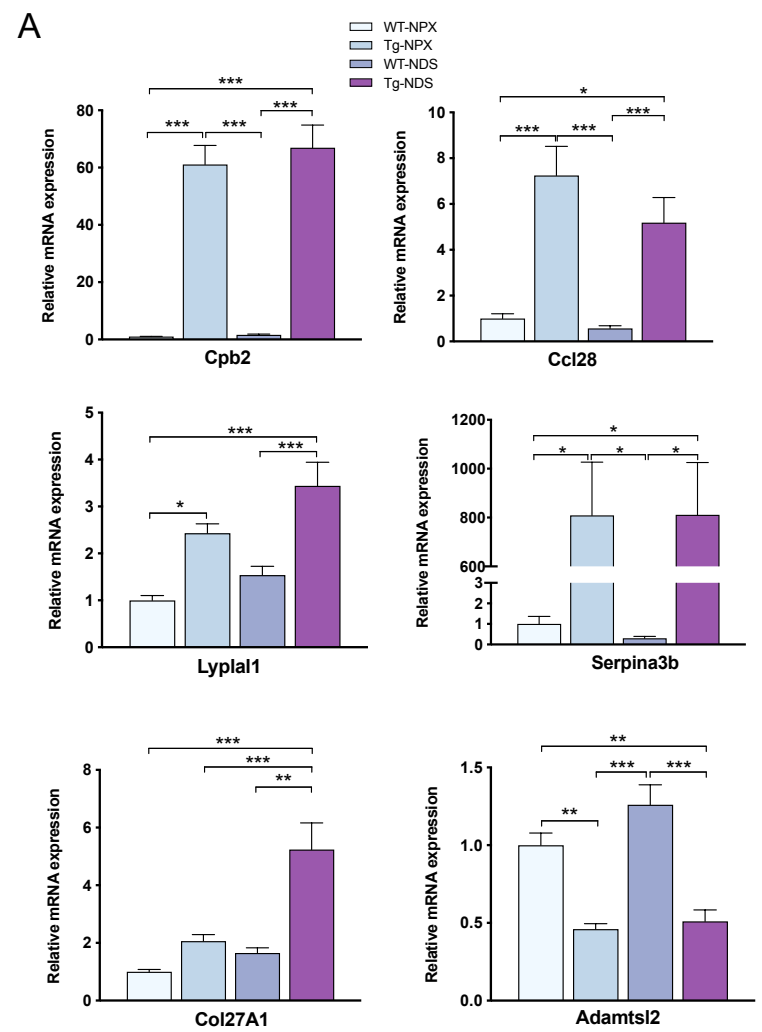

B

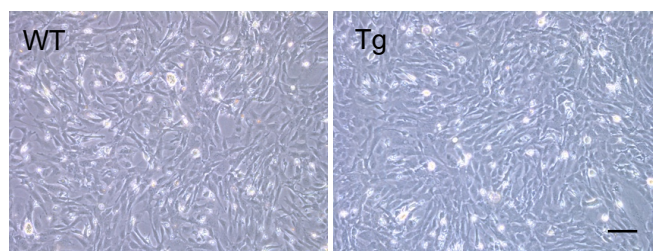

C

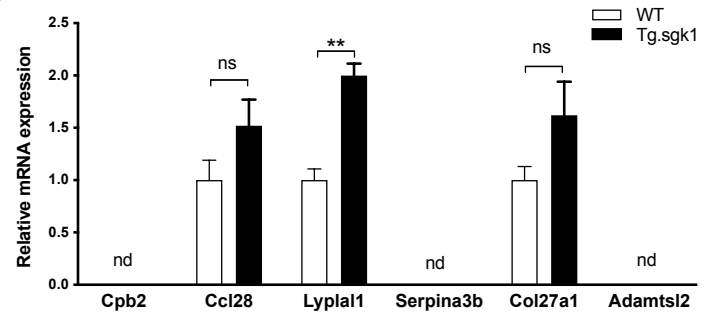

